\title{
A QUARTERLY FISCAL DATABASE FOR THE EURO AREA BASED ON INTRA-ANNUAL FISCAL INFORMATION
}

by Joan Paredes, Diego J. Pedregal and Javier J. Pérez 


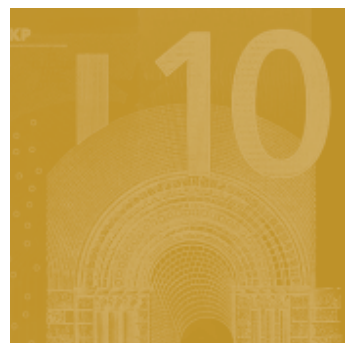

\title{
A QUARTERLY FISCAL DATABASE FOR THE EURO AREA BASED ON INTRA-ANNUAL FISCAL INFORMATION
}

\author{
by Joan Paredes ${ }^{2}$, Diego J. Pedregal ${ }^{3}$ \\ and Javier J. Pérez ${ }^{4}$
}

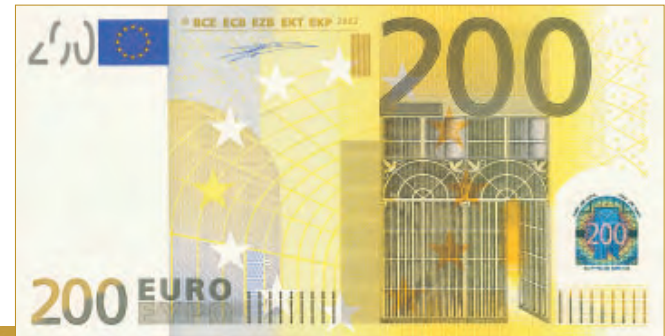

In 2009 all ECB publications feature a motif taken from the $€ 200$ banknote.
This paper can be downloaded without charge from http://www.ecb.europa.eu or from the Social Science Research Network electronic library at http://ssrn.com/abstract_id $=1520524$.

I The views expressed in this paper are those of the authors and not necessarily those of the European Central Bank or the Bank of Spain. We thank seminar participants at the European Central Bank, Jacopo Cimadomo, Todd Clark, Günter Coenen, Francisco de Castro, Daniel Garrote, Domenico Giannone, Markus Kirchner, Albert Marcet, Henri Maurer, Agustín Maravall, Ad van Riet, Matthias Trabandt, and colleagues at the ECB's Fiscal Policies Division and Government Finance Statistics Unit, for useful comments and suggestions. We also thank Lorenzo Forni, José Emilio Gumiel, Alexandru Isar, Sandro Momigliano and A. Jesús Sánchez for help with the data. Pedregal acknowledges financial support of the Spanish Education and Science Ministry under project SEJ2006-14732 (ECON). The opinions expressed in the paper are those of the authors and do not necessarily reflect those of the European Central Bank or the Eurosystem. 2 European Central Bank, Kaiserstrasse 29, D-603II Frankfurt am Main, Germany; e-mail: joan.paredes@ecb.europa.eu 3 Uuniversidad. Castilla-La Mancha, Real Casa de la Misericordia C/ Altagracia 50, I307I Ciudad Real, España; e-mail: diego.pedregal@uclm.es 
(C) European Central Bank, 2009

Address

Kaiserstrasse 29

60311 Frankfurt am Main, Germany

Postal address

Postfach 160319

60066 Frankfurt am Main, Germany

Telephone

+496913440

Website

http://www.ecb.europa.eu

\section{Fax}

+496913446000

All rights reserved.

Any reproduction publication and reprint in the form of a different publication, whether printed or produced electronically, in whole or in part, is permitted only with the explicit written authorisation of the ECB or the author(s).

The views expressed in this paper do not necessarily reflect those of the European Central Bank

The statement of purpose for the ECB Working Paper Series is available from the ECB website, http://www.ecb.europa. eu/pub/scientific/wps/date/html/index. en.html

ISSN 1725-2806 (online) 


\section{CONTENTS}

Abstract

Non-technical summary

1 Introduction

2 The data

2.1 Input data

2.2 Statistical issues

3 The models

3.1 General setup

3.2 Temporal aggregation

3.3 Interpolation: smoothing vs filtering?

3.4 The models for the euro area aggregates

4 Construction of a historical fiscal database

4.1 A first look at the database

4.2 Basic dynamic properties of the database and comparison with existing alternatives

4.3 Some stylised facts of the database

5 Construction of a real-time database for government revenue and expenditure

6 Conclusions

References

Appendices

Tables and figures

European Central Bank Working Paper Series 


\begin{abstract}
The analysis of the macroeconomic impact of fiscal policies in the euro area has been traditionally limited by the absence of quarterly fiscal data. To overcome this problem, we provide two new databases in this paper. Firstly, we construct a quarterly database of euro area fiscal variables for the period 1980-2008 for a quite disaggregated set of fiscal variables; secondly, we present a real-time fiscal database for a subset of fiscal variables, composed of biannual vintages of data for the euro area period (2000-2009). All models are multivariate, state space mixed-frequencies models estimated with available national accounts fiscal data (mostly annual) and, more importantly, monthly and quarterly information taken from the cash accounts of the governments. We provide not seasonally- and seasonally-adjusted data. Focusing solely on intra-annual fiscal information for interpolation purposes allows us to capture genuine intra-annual "fiscal" dynamics in the data. Thus, we provide fiscal data that avoid some problems likely to appear in studies using fiscal time series interpolated on the basis of general macroeconomic indicators, namely the well-known decoupling of tax collection from the evolution of standard macroeconomic tax bases (revenue windfalls/shortfalls).
\end{abstract}

Keywords: Euro area, Fiscal policies, Interpolation, Unobserved Components models, Mixed frequencies.

JEL Classification: C53, E6, H6. 


\section{Non-technical Summary}

Macroeconomic analysis with aggregated euro area data has become a common place over the last decade. This is not surprising, given that monetary policy for the European countries that have been adopting the euro currency since January 1999 is set by the European Central Bank (ECB). Therefore, the construction of historical data for the euro area has been part of the academic agenda and the agenda of the ECB over the past few years. Even though fiscal policy remains a national issue, interactions between monetary and fiscal policies are carefully monitored by the monetary authority and there is an increasing interest about this topic. In particular, in circumstances like the current ones in which a number of discretionary fiscal policy packages are put forward by euro area governments, the assessment of the impact of fiscal policies on euro area GDP and prices, and the constraints fiscal policy might impose on monetary policy over the medium term is a relevant endeavour.

The appropriate assessment of the impact of fiscal policies at the euro area wide level is restricted by the limitations of available quarterly data for the relevant fiscal variables in national accounts terms. The whole fiscal surveillance process at the European level is designed on the basis of annual data. The fact that budgetary plans are prepared following an annual budgetary cycle, typically in the framework of annual models, and the discretionary nature of many government measures set up for the entire year, have traditionally limited the interest in high-frequency fiscal data. Nevertheless, a recent strand of the literature has shown that intraannual fiscal data, when modelled appropriately, contains extremely valuable and useful information for forecasting annual fiscal aggregates, enabling earlier detection of episodes of fiscal deterioration (or improvement) than traditional methods.

Thus, the issue addressed in this paper is the construction of a quarterly fiscal database for the euro area for the period 1980-2008, solely based on intra-annual fiscal information, on the basis of multivariate, state-space mixed-frequencies models. The models are estimated with annual and quarterly national accounts fiscal data and government monthly cash accounts data.

We provide a quite disaggregated set of nominal fiscal variables for the General Government sector in ESA95 terms, seasonally and non-seasonally adjusted, in order to make the database a usable input for the estimation of macroeconomic models or for applied empirical studies.

In addition, we also provide a real-time database for aggregated total government revenue and expenditure (and thus government net lending) for bi-annual vintages of data for the euro area period, 2000-2009 (with historical data starting in 1980 though), thus contributing to the production of real-time datasets for the euro area. This additional database, even though being more limited in coverage than our baseline database, due to problems with data availability, is 
fit for the real-time analysis of fiscal policies in the euro area, an issue shown to be of relevance for the analysis of monetary policy.

Our databases make use of only intra-annual fiscal information. This is a relevant point for further research devoted to the integration of interpolated intra-annual fiscal variables in more general macroeconomic studies, because it allows us to capture genuine intra-annual "fiscal" dynamics in the data. This is very important because although revenues and expenditure (more limited via mainly only unemployment benefits) may be endogenous to GDP or any other tax base proxy (i.e. private consumption and so forth), the relationship at most between these variables are indirect and very difficult to estimate. One reason is the well-known decoupling of tax collection from the evolution of macroeconomic tax bases (revenue windfalls/shortfalls).

The fiscal databases developed in this paper (baseline database and real-time database) present the potential of constituting a useful input for broader macroeconomic analyses using euro area data and involving the use of fiscal variables, exercise currently conducted either with annual data or with limited availability of quarterly fiscal information. Studies of this type that have recently received renewed attention include simulation exercises to assess the impact fiscal stimulus packages, analyses of the interaction between monetary and fiscal policies, or the estimation of fiscal policy rules. 


\section{Introduction}

Macroeconomic analysis with aggregated euro area data has become a common place over the last decade. ${ }^{1}$ This is not surprising, given that monetary policy for the European countries that have been adopting the euro currency since January 1999 is set by the European Central Bank (ECB). Therefore, the construction of historical data for the euro area has been part of the academic agenda and the agenda of the ECB over the past few years (see Beyer et al., 2001, Anderson et al., 2007, Fagan et al., 2001, 2005). Even though fiscal policy remains a national issue, interactions between monetary and fiscal policies are carefully monitored by the monetary authority (see for example, ECB, 2008, 2009, Duisenberg, 2003). In particular, in circumstances like the current ones in which a number of discretionary fiscal policy packages are put forward by euro area governments, the assessment of the impact of fiscal policies on euro area GDP and prices, and the constraints fiscal policy might impose on monetary policy over the medium term is a relevant endeavour.

The appropriate assessment of the impact of fiscal policies at the euro area wide level is restricted by the limitations of available quarterly data for the relevant fiscal variables in national accounts terms. The whole fiscal surveillance process at the European level is designed on the basis of annual data. The fact that budgetary plans are prepared following an annual budgetary cycle, typically in the framework of annual models, and the discretionary nature of many government measures set up for the entire year, have traditionally limited the interest in high-frequency fiscal data. Nevertheless, a recent strand of the literature has shown that intraannual fiscal data, when modelled appropriately, contains extremely valuable and useful information for forecasting annual fiscal aggregates, enabling earlier detection of episodes of fiscal deterioration (or improvement) than traditional methods (Pérez, 2007, Silvestrini et al., 2008, Onorante et al., 2009, Pedregal and Pérez, 2009).

Thus, the issue addressed in this paper is the construction of a quarterly fiscal database for the euro area for the period 1980-2008, solely based on intra-annual fiscal information, on the basis of multivariate, state-space mixed-frequencies models. ${ }^{2}$ The models are estimated with annual and quarterly ${ }^{3}$ national accounts fiscal data and government monthly cash accounts data.

\footnotetext{
${ }^{1}$ See as a few examples of a growing literature Forni et al. (2009), Ratto et al. (2009), Fagan et al. (2005), or Smets and Wouters (2003).

2 Along the lines of Harvey and Chung (2000), Moauro and Savio (2005), Proietti and Moauro (2006).

3 Quarterly government finance statistics for the euro area are available for the period starting in 1999Q1, in nominal, non-seasonally adjusted terms, see European Commission (2002a, 2002b, 2006). The data started to be published by the European Central Bank in August 2004 (only for the euro area aggregate, see ECB, 2004), and subsequently by Eurostat itself. For further details see European Commission (2007) and Pedregal and Pérez (2009).
} 
We provide a quite disaggregated set of nominal fiscal variables for the General Government sector in ESA95 terms, ${ }^{4}$ seasonally and non-seasonally adjusted, in order to make the database a usable input for the estimation of macroeconomic models (like ECB's AWM or NAWM, see Fagan et al., 2001, 2005, and Coenen et al., 2008, respectively) or for applied empirical studies. On the revenue side of government accounts the database covers total government revenue, direct taxes (with a proxy for the breakdown between direct taxes paid by households and firms), social security contributions (with a proxy for the breakdown between contributions paid by employers and others), and total indirect taxes. On the expenditure side, it covers total expenditure, social payments (of which also unemployment benefits), interest payments, subsidies, government investment and government consumption. Given the relevance of the latter variable (part of the demand side of GDP), we provide the breakdown between nominal and real government consumption, the breakdown between government wage and non-wage consumption expenditure, and government employment. The net lending of the government, a key policy variable, can be computed as the difference between total revenues and total expenditures.

In addition, we also provide a real-time database for aggregated total government revenue and expenditure (and thus government net lending) for bi-annual vintages of data for the euro area period, 2000-2009 (with historical data starting in 1980 though), thus contributing to the production of real-time datasets for the euro area, a relevant issue as pointed out by Croushore and Stark $(2001,2003) .{ }^{5}$ This additional database, even though being more limited in coverage than our baseline database, due to problems with data availability, is fit for the real-time analysis of fiscal policies in the euro area, an issue shown to be of relevance for the analysis of monetary policy (see Orphanides, 2001, or Croushore and Evans, 2006). ${ }^{6}$

Our databases make use of only intra-annual fiscal information. This is a relevant point for further research devoted to the integration of interpolated intra-annual fiscal variables in more general macroeconomic studies, because it allows us to capture genuine intra-annual "fiscal" dynamics in the data. This is very important because although government revenues and expenditures (e.g. unemployment benefits) may be endogenous to GDP or any other tax base proxy (e.g. private consumption for indirect tax collection) the relationship between these variables is at most indirect and extremely difficult to estimate. The decoupling of tax collection

\footnotetext{
${ }^{4}$ ESA95: European System of National Accounts, see http://circa.europa.eu/irc/dsis/nfaccount/info/data/ESA95.

5 For the euro area, the Euro Area Business Cycle Network (EABCN) maintains and develops a Real Time Database (RTDB) of time series of several macroeconomic variables, based on series reported in the ECB's Monthly Bulletins. Regarding quarterly fiscal data, the EABCN RTDB contains vintages of quarterly real government consumption and the deflator of government consumption. For details see Giannone et al. (2006) and the EABCN reserved space at http://www.eabcn.org/data/rtdb/index.htm.
}

${ }^{6}$ For the analysis of real-time fiscal policies, using annual data and forecasts, see Cimadomo (2008). 
from the evolution of macroeconomic tax bases (revenue windfalls/shortfalls) is by now a proved stylised fact. ${ }^{7}$ We instead use directly fiscal data for interpolation purposes, which overcomes the problem of modelling an indirect relationship which is time-varying.

Existing databases that contain quarterly fiscal variables for the euro area are the AWM database 8 initially developed by Fagan et al. (2001, 2005), and the recent dataset that accompanies the DSGE model by Forni et al. (2009). The interpolated annual fiscal variables in these two datasets were mainly constructed using as main ingredients GDP and other macroeconomic indicators. While this approach might be valid in certain circumstances on the grounds of economic model consistency, it is also true that both datasets are affected by the serious critiques laid out in the previous paragraph.

Turning to a deeper description of the merits of our database, as mentioned above, we provide seasonally and non-seasonally adjusted series, which are consistently and jointly estimated within our models. The issue of seasonal adjustment of quarterly fiscal variables in Europe is an important one, as signalled in European Commission (2007). Currently, available quarterly ESA95 official figures are presented only in non-seasonally adjusted terms, given the short time span available (the starting period is 1999Q1), what makes difficult the economic analysis with those figures. Indeed, adjusting in a robust way for seasonality such short time series is a difficult endeavour. In this sense, given that we use a broad set of information and model explicitly seasonality for the whole set of series included in our models, for the period 1980Q12008Q4, we are in a position to provide, in particular, seasonally adjusted series computed in a robust way for the period for which the official statistics are available (1999Q1 onwards). ${ }^{9}$

The approach followed in this paper is an indicator-based one. This means that we do not aggregate data of the individual euro area member states as such. Instead, we use aggregated annual data as provided by the European Commission and (when available) quarterly euro area

\footnotetext{
7 The term revenue shortfalls (windfalls) is used here to describe government revenues which fall short of (are in excess of) what would be expected in view of the impact of legislation changes and the actual or projected development of key macroeconomic aggregates (notably compensation of employees, operating surplus and private consumption) on which the cyclical adjustment of tax revenues is based. This is often caused by the fact that the actual tax base behaves differently to the macroeconomic variable used to proxy for it. For example, receipts from corporate income taxes depend, inter alia, on the extent of losses from previous periods that are carried forward and offset against current profits, which is not reflected in the evolution of the operating surplus (i.e. the National Accounts measure of profits).

8 See http://www.eabcn.org/data/awm/index.htm.

9 The main aim of our paper is to provide interpolated, raw (non-seasonally adjusted) fiscal data. Given that the type of models that we use encompasses the estimation of a seasonal component, we also provide model-consistent, seasonally-adjusted series. Nevertheless, seasonal adjustment is not a key issue of our paper. In this respect, some empirical applications making use of our data, like those that may incorporate seasonally-adjusted macroeconomic data (by some standard method like TRAMO/SEATS, see for example Gómez and Maravall, 1996) may call for the seasonal adjustment of our raw data with methods that are comparable to those applied to the other variables incorporated in the analysis.
} 
data by Eurostat as anchors for the interpolation, ${ }^{10}$ while at the same time we set up statistical models that incorporate ingredients that closely resemble those used to compile available quarterly government finance statistics data by Eurostat, for the biggest euro area economies, namely Germany, France, Italy, Spain and the Netherlands. We do so for several reasons. Firstly, to maximize data availability, and in particular, the length of the available series; an aggregation-based approach would have blocked many time series, and seriously limited the length of the feasible ones. In this respect it is worth mentioning that all the ingredients of the dataset are publicly available, i.e. we made no use of restricted or private information. Secondly, to avoid the controversial issues of weighting schemes, as discussed in Beyer et al. (2001), Bosker (2006), Brüggemann and Lütkepohl (2006) or Anderson et al. (2007). Thirdly, to overcome the impossibility of following an accounting approach like the one used by statistical agencies, not feasible for the sample period chosen and given the limited information available. Nonetheless, as regards the latter point, we tried to follow to the extent possible the principles outlined in European Commission (2002a, 2002b, 2006) as regards the compilation of government finance statistics: use of direct information from basic sources (public accounts' data), computation of "best estimates", consistency of quarterly and annual data.

The rest of the paper is organised as follows. Section 2 describes the input data used and discuss general statistical issues. Section 3 describes our methodological approach. Section 4 describes the construction of the quarterly fiscal database, including a comparison with alternative datasets and shows some stylised facts of the data. Section 4 also presents a methodological discussion of interpolation alternatives, as regards the use of smoothed vs. filtered series. Section 5, in turn, presents and discusses the real-time fiscal database. Finally, Section 6 concludes.

\section{The data}

\subsection{Input data}

As mentioned in the Introduction, the approach followed in this paper is an approach based on the use of indicators. This means that we do not aggregate data of the individual euro area member states as such to compute a euro area aggregate. Instead, we use ESA95 euro area data at the lower frequencies (annual, quarterly) and interpolate the missing values at the higher frequency (quarterly, monthly) using fiscal variables from the public accounts, available at that latter frequency.

\footnotetext{
10 The euro area definition we use comprises the following countries: Belgium, Germany, Ireland, Greece, Spain, France, Italy, Luxembourg, Netherlands, Austria, Portugal and Finland.
} 
The euro area definition we use comprises the following countries: Belgium, Germany, Ireland, Greece, Spain, France, Italy, Luxembourg, Netherlands, Austria, Portugal and Finland. The bulk of the annual euro area data in ESA95 terms for the period 1991-2008 is taken from AMECO, the database of the Directorate-General for Economic and Financial Affairs of the European Commission. ${ }^{11}$ There are two exceptions to this source: the series for annual euro area direct taxes on corporations for the period 1980-2008 was obtained from the OECD Economic Outlook database, while the series for employers' social contributions (for the period 19912008) was taken from Eurostat's ESA95 database.

For the prior period 1980-1990, we had to account for the presence of a break in accounting standards (ESA79 to ESA95) and the German unification. In order to obtain homogeneous levels for the whole period 1980-2008, we removed level discontinuities by applying backwards the growth rates of the series in ESA79 terms (that exclude East Germany) to the levels of the ESA95 series. Quarterly figures for the euro area aggregate for the period 1999Q1-2008Q4 are taken from Eurostat, and are only available non-seasonally adjusted. ${ }^{12}$ The impact of one-off proceeds from the allocation of mobile licenses (UMTS) that sizeably distort some years was removed from the relevant series.

Quarterly and monthly fiscal variables (indicators) for the biggest euro area economies, namely Germany, France, Italy, Spain and the Netherlands, are taken from Eurostat (available ESA95 series), several national sources, the Bank of International Settlements (BIS), and other sources, as described in Table 1. When necessary, country variables are set into euros using the official fixed euro conversion rates. Also, when necessary, German series were corrected for the impact of the Unification, as explained in the previous paragraph. For additional details on some data sources of monthly/quarterly "indicator" series, the interested reader can also consult Onorante et al. (2009). Finally, annual information in ESA79/ESA95 definitions for the countries is taken from the AMECO database when needed, and quarterly information following ESA95 standards from Eurostat, as mentioned above for the euro area aggregate.

\subsection{Statistical issues}

As stated above, Eurostat, on the basis of data provided by EU National Statistical Institutes, provides quarterly non-financial government data for the euro area for the period starting in 1999Q1. The compilation practices follow the guidelines of the manual on quarterly nonfinancial accounts for general government (see European Commission, 2006). Using the latter accounting approach to extend back in the past existing euro area fiscal time series is not a

\footnotetext{
11 Available at http://ec.europa.eu/economy_finance/db_indicators/db_indicators8646_en.htm.

12 At http://epp.eurostat.ec.europa.eu/portal/page/portal/government_finance_statistics/data/database.
} 
feasible endeavour, given the limited information available. That is why we chose in this paper an econometric approach rather than an accounting approach. Nevertheless, we tried to follow to the extent possible some of the principles outlined in the manual on quarterly non-financial accounts for general government: use of direct information from basic sources (public accounts' data), computation of "best estimates", and consistency of quarterly and annual data.

In this respect, we chose intra-annual data from the public accounts of the individual countries, along the lines of the statement of the manual that quarterly data shall be based on direct information available from basic sources, such as for example public accounts or administrative sources.

More importantly, the manual exposes that the quarterly data and the corresponding annual data have to be consistent, a constraint that our database fulfils. As regards the coherence of quarterly data with annual rules, the discussion in European Commission (2002a, 2002b, 2006) shows that there is some room for econometric estimation of intra annual fiscal variables. This is the case for two main reasons, highlighted in the previous references. Firstly, ESA95 does not consider the quarterly aspects of taxes and social payments with sufficient precision to ensure clarity of interpretation in all situations; this is because, when discussing non-financial accounts, the ESA95 guiding documents occasionally take a perspective which assumes an annual reference period is in mind, thus remaining silent on which quarter within a particular annual reference period is involved. Secondly, it is also the case that many accounting or legal events are annual events by definition (e.g. a tax levied in a complete year); this fact does not present a problem for the statistician compiling annual data (there is no need to establish the amount and time of recording to a particular annual reference period), but do pose problems for the compiler of quarterly data, that needs to attribute revenue and expenditure not merely to a reference year but also to quarters within that year.

\section{The models}

\subsection{General setup}

The basic model is of the Unobserved Component Model class known as the Basic Structural Model (Harvey, 1989), that decomposes a set of time series in unobserved though meaningful components from an economic point of view (mainly trend, seasonal and irregular). The exposition in this subsection follows closely Harvey (1989), Pedregal and Young (2002) and Pedregal and Pérez (2009).

The model is multivariate, and may be written as equation (1), where $t$ is a time sub-index measured in months (for models set up at the monthly frequency), 


$$
\left[\begin{array}{l}
z_{t} \\
\mathbf{u}_{t}
\end{array}\right]=\mathbf{T}_{t}+\mathbf{S}_{t}+\mathbf{e}_{t}
$$

$\left[\mathrm{z}_{\mathrm{t}}, \mathbf{u}_{\mathrm{t}}\right]^{\mathrm{T}}, \mathbf{T}_{\mathrm{t}}, \mathbf{S}_{\mathrm{t}}$ and $\mathbf{e}_{\mathrm{t}}$ denote the $\mathrm{m}$ dimensional output time series (broken down into a scalar output, $\mathrm{z}_{\mathrm{t}}$, and indicators, $\mathbf{u}_{\mathrm{t}}$ ), trend, seasonal and irregular components, respectively. Equation (1) is in fact a set of observation equations in a State Space system, which has to be completed by the standard transition or state equations. The state equations qualify the dynamic behaviour of the components, and a full model may be built by block concatenation of the individual components. The transition equations for models of the trend and seasonal components are a Local Linear Trend and the Trigonometric Seasonal in equation (2), where $\mathbf{D}_{\mathrm{t}}$ and $\mathbf{S}_{\mathrm{it}}{ }^{\prime}$ are additional states necessary to define the components; $\mathbf{I}$ and $\mathbf{0}$ are the identity matrix and a square block of zeros of dimension $m ; \mathbf{w}_{\mathrm{j}}$ and $\mathbf{w}_{\mathrm{j}}{ }^{\prime}(\mathrm{j}=0,1, \ldots, 6)$ are multivariate Gaussian white noises serially independent and independent of each other; and $\omega_{i}(j=0,1, \ldots, 6)$ are the fundamental frequency of the seasonal component and its harmonics.

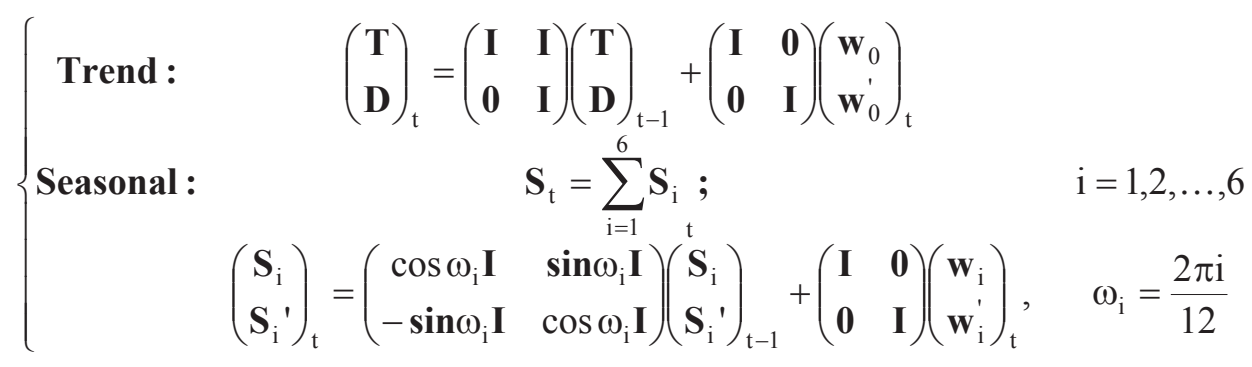

A full BSM model may be written in compact form as a composite of a set of Transition and Observation Equations, like equation (3) written in compact form (see details in Harvey, 1989),

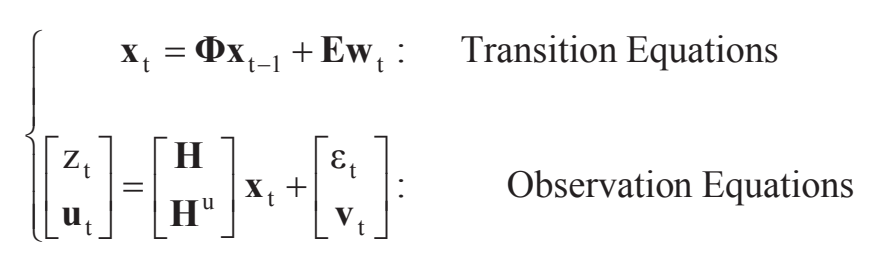

where $\mathbf{w}_{\mathrm{t}} \sim \mathrm{N}\left(\mathbf{0}, \boldsymbol{\Sigma}_{\mathrm{w}}\right), \boldsymbol{\varepsilon}_{\mathrm{t}} \sim \mathrm{N}\left(\mathbf{0}, \boldsymbol{\Sigma}_{\varepsilon}\right)$ and $\mathbf{v}_{\mathrm{t}} \sim \mathrm{N}\left(\mathbf{0}, \boldsymbol{\Sigma}_{\mathrm{v}}\right) . \mathbf{x}_{\mathrm{t}}$ is the concatenation of the trend components $\mathbf{T}_{\mathrm{t}}$ and seasonal components $\mathbf{S}_{\mathrm{it}}(\mathrm{i}=1,2, \ldots, 6)$. The general consensus in this type of multivariate models in order to enable the identifiability is to build SUTSE models (Seemingly Unrelated Structural Time Series). This means that components of the same type interact among them for different time series, but are independent of any of the components of different types. In addition, relations are only allowed through the covariance structure of the vector noises $\mathbf{v}_{t}$ and $\varepsilon_{t}$, but never through the system matrices directly. This allows that, trends of different time series may relate to each other, but all of them are independent of both the seasonal and irregular components. 
Given the structure of system (2) and the information available, the Kalman Filter and Fixed Interval Smoother algorithms provide an optimal estimation of states $\mathbf{x}_{\mathrm{t}}$. Maximum likelihood in the time domain provides optimal estimates of the unknown system matrices, which in the present context are just covariance matrices of all the vector noises involved in the model.

\subsection{Temporal aggregation}

The mixture of frequencies, and the estimation of models at the quarterly frequency, implies combining variables that at the quarterly frequency can be considered as stocks with those being pure flows. An annual ESA95 series cast into the quarterly frequency is a set of missing observations for the first three quarters of the year and the observed value assigned to the last month of each year. Theoretically the annual ESA95 series would be obtained from a quarterly ESA95 series by summation of the 4 quarters of a year (Q1 to Q4) had them been available.

In the same fashion, for monthly models a quarterly ESA95 series cast at the monthly frequency encompasses missing observations for the first and the second month of each quarter, while the quarterly observation would be assigned to the last month of each quarter. Notionally, the quarterly ESA95 series would be obtained from a monthly ESA95 series by summation of the 3 months of each quarter had them been available. Likewise, an annual ESA95 series cast into the monthly frequency is a set of missing observations for the first months of the year (January to November) and the observed value assigned to the last month of each year (December). The annual ESA95 series would be obtained from a monthly ESA95 series by summation of the 12 months of a year (January to December) had them been available.

In order to set up a model in which temporal aggregation is taken into account explicitly, an accumulator variable has to be defined, as follows

$$
\mathrm{C}_{\mathrm{t}}= \begin{cases}0, & \mathrm{t}=\text { every January (monthly data) / first quarter (quarterly data) } \\ 1, & \text { otherwise }\end{cases}
$$

Adding equation (4)

System (3) is exactly equivalent to a model in which the state vector is extended to include the output variables and the vector of transition noises is also extended with the corresponding observed noises. Then, adding equation (4) to th so extended system and re-arranging, leads to the following model

$$
\begin{aligned}
& {\left[\begin{array}{l}
\mathrm{z}_{\mathrm{t}} \\
\mathbf{x}_{\mathrm{t}}
\end{array}\right]=\left[\begin{array}{cc}
\mathrm{C}_{\mathrm{t}} \otimes \mathbf{I} & \mathbf{H} \boldsymbol{\Phi} \\
\mathbf{0} & \boldsymbol{\Phi}
\end{array}\right]\left[\begin{array}{l}
\mathrm{z}_{\mathrm{t}-1} \\
\mathbf{x}_{\mathrm{t}-1}
\end{array}\right]+\left[\begin{array}{cc}
1 & \mathbf{H} \\
\mathbf{0} & \mathbf{E}
\end{array}\right]\left[\begin{array}{l}
\varepsilon_{\mathrm{t}} \\
\mathbf{w}_{\mathrm{t}}
\end{array}\right]} \\
& {\left[\begin{array}{l}
\mathrm{z}_{\mathrm{t}} \\
\mathbf{u}_{\mathrm{t}}
\end{array}\right]=\left[\begin{array}{cc}
\mathbf{I} & \mathbf{0} \\
\mathbf{0} & \mathbf{H}^{\mathrm{u}}
\end{array}\right]\left[\begin{array}{l}
\mathrm{z}_{\mathrm{t}} \\
\mathbf{x}_{\mathrm{t}}
\end{array}\right]+\left[\begin{array}{l}
\mathbf{0} \\
\mathbf{I}
\end{array}\right] \mathbf{v}_{\mathrm{t}}}
\end{aligned}
$$


It is worth noticing that model (5) has one time varying system matrix due to the introduction of the accumulator variable. Given model (5), the estimation problem consists of finding the optimal estimates of the mean and covariance of the state vector, conditional to all the data in the sample. The widespread general tools to perform this operation in a State Space framework are the Kalman Filter (KF, Kalman, 1960, Kalman and Bucy, 1961) and the Fixed Interval Smoothing (FIS, Bryson and Ho, 1969) algorithms. The KF algorithm runs forward and yields a filtered estimate of the state vector at every sample $t$, based on the time series data up to sample t. The FIS algorithm runs backwards and produces a smoothed estimate of the states which, at every sample $t$, is based on all samples of the data. This means that, as more information is used in the later estimate, its Mean Square Error cannot be greater than the former.

The use of models of type (5) and the estimation procedures described in the previous paragraph, allows the estimation of models with unbalanced data sets, i.e. components of the matrix $\left\{\mathbf{u}_{t}\right\}$ with different sample lengths. This is a feature of relevance for the construction of the database at hand, given occasional differences in temporal coverage of country indicators.

\subsection{Interpolation: smoothing vs filtering?}

It is well known that the FIS and KF algorithms allow inherently for a number of useful operations, being interpolation, the most important in the present context. If missing data anywhere within the data set are detected, then the filtering and smoothing algorithms simply replace the missing samples by their expectations, based on the State Space model and the data.

The empirical application in our paper concerns fiscal variables that incorporate a number of discretionary fiscal policy events. One may claim that using the FIS algorithm for interpolation may lead to the allocation of part of the future impact of a given policy measure to the present given that the FIS algorithm uses information from $t+1$ onwards for interpolation at time $t$. We do not think this critique is relevant for the aims of this paper, provided interpolation is understood as the reconstruction of missing values as close as possible to what they would have been in case the data were known.

The FIS algorithm may be seen as a sophisticated centred moving average, with weights time varying depending on the model and on time t. In other words, in general, the smoothed (interpolated) components of a UC model would imply using information from the past, but also from the future for state estimation at each time t. However, as the extant literature clearly shows, ${ }^{13}$ the use of all the information of the sample is the optimal way to proceed in order to

\footnotetext{
13 Despite the generality and advantages of the KF and FIS algorithms, there are other alternative algorithms for the estimation of the state vector, most of them equivalent (see e.g. Young and Pedregal, 1999). That is the case of the Bayesian algorithm that takes advantage of a nice interpretation of the KF and FIS recursive algorithms in terms of Bayes theory (West and Harrison, 1989); the Wiener-Kolmogorov-Whittle classical filter, still used by some
} 
find the optimal estimation of a missing value. Even when just the KF is used, the normal procedure is to use future information implicitly by estimation of the parameters of the model with the full dataset. Interpolating a time series by nowcasting or true forecasting (i.e. using parameter estimates up to the moment when the interpolation is required) is clearly sub-optimal and may contradict the meaning of interpolation, in the sense that there is information useful for the missing value estimation that is not used. The FIS algorithm helps unveiling much better the data generating process of the time series of interest. In Appendix A we perform some simulations that reinforce this latter point.

Another essential advantage of the smoothed estimates in the present context is that they fulfil exactly the time aggregation constraints imposed on model (5), i.e. due to such constraints, the smoothed intra annual interpolates add up exactly to the available annual (quarterly) figure and the uncertainty when any data point is known is strictly zero. The KF would not produce such exact results, apart that the uncertainty around any estimate would be much greater.

For the reasons stated above we will favour the series produced with the FIS algorithm, and focus on the latter in the presentation of the database in the next Section. Nevertheless, as a check and for user convenience, we also provide the whole database interpolated using the KF algorithm in the companion database to this paper (see Appendix $\mathrm{C}$ for a description).

\subsection{The models for the euro area aggregates}

For each specific variable considered in this study, models of type (5) are estimated. In each model, the variable $\left\{\mathrm{z}_{\mathrm{t}}\right\}$ corresponds to the target time series to be interpolated, composed of annual observations for the period 1980-1998, and quarterly observations for the period 19992008. The vector of indicator variables $\left\{\mathbf{u}_{t}\right\}$, in turn, comprises a set of variables with monthly (for monthly models) or quarterly (for quarterly models) observations, typically (but not always) available for the full period 1980-2008.

Without loss of generality, and for homogeneity reasons related to the availability of indicators, all the variables of the quarterly fiscal database will be interpolated using models of type (5) set up at the quarterly frequency, while the variables of the real-time database will be interpolated by means of models of type (5) set up at the monthly frequency.

Estimation of model (5) provides estimates for the missing values in $\left\{\mathrm{Z}_{\mathrm{t}}\right\}$ (missing quarterly/monthly data points) and estimates of $\mathbf{x}_{\mathbf{t}}$ the vector comprising the unobserved components that include the estimated seasonal components, as defined in equation (2). Thus, it is possible to compute model-consistent seasonally-adjusted interpolated series for the target

approaches to signal extraction (e.g. Gómez and Maravall, 1998); and some deterministic optimisation methods proposed for signal extraction (see Pedregal and Young, 2002, and references therein). 
variables $\left\{\mathrm{z}_{\mathrm{t}}\right\}$ just by subtraction of the correspondingly estimated seasonal components in $\mathbf{x}_{\mathrm{t}}$ from $\left\{z_{\mathrm{t}}\right\}$.

\section{Construction of a historical fiscal database}

The structure of the database and naming conventions are displayed in Table 2. The variables contained in the quarterly fiscal database are the following. On the revenue side of government accounts, the database includes total government revenue, direct taxes, social security contributions, and total indirect taxes. On the expenditure side, it incorporates total expenditure, social payments, unemployment benefits, interest payments, subsidies, government investment and government consumption, the latter in nominal and real terms, a government wage consumption expenditure, government employment, and purchases of goods and services. The net lending of the government, a key policy variable, can be computed as the difference between total revenues and total expenditures.

For all euro area models - equation (5) - the vector $\left\{\mathrm{z}_{\mathrm{t}}\right\}$ encompasses annual ESA95 euro area data for the period 1980-1998, and quarterly, non-seasonally adjusted, ESA95 data for the period 1999Q1-2008Q4, taken from the sources described in Section 2 as available in April 2009. On the other hand, as it is clear from the description of data sources in Table 1, in some instances it was necessary to use more than one source of intra-annual information in order to compute the indicator variable finally included in the euro area model within the vector $\left\{\mathbf{u}_{t}\right\}$. In Appendix B we provide a quite detailed description of the implementation of the general methodology and the data inputs described in the case of each one of the variables included in our study, and also the description of the components of $\left\{\mathbf{u}_{\mathrm{t}}\right\}$ in each case.

A final remark on the dimensionality of the models is worth mentioning. In order to reduce the dimensionality of our models and somewhat avoid the "curse of dimensionality" we opted for variable-by-variable models. By this we mean that, in all cases, $\left\{\mathrm{z}_{\mathrm{t}}\right\}$ encompasses just one time series (annual/quarterly), and $\left\{\mathbf{u}_{t}\right\}$ the set of indicators corresponding to the latter variable, with a maximum of five indicators (one per country for each variable). The alternative would have been to run models in which $\left\{\mathrm{z}_{\mathrm{t}}\right\}$ would have included several variables, and thus $\left\{\mathbf{u}_{\mathrm{t}}\right\}$ would have been a matrix with indicators by blocks for each component of $\left\{\mathrm{z}_{\mathrm{t}}\right\}$. Examples of other suitable models include a joint model for TOR and TOE, as in Pedregal and Pérez (2009), i.e. $\left\{z_{t}\right\}=\{$ TOR, TOE $\}$, a joint model for the revenue side of the governments accounts, i.e. $\left\{z_{t}\right\}=$ $\{$ TOR, DTX, SCT, TIN, OTOR $\}$, or a joint model for the expenditure side, i.e. $\left\{z_{t}\right\}=\{$ TOE, THN, GCN, GIN, INP, SIN, OTOE\}. We preferred to use for interpolation purposes more parsimonious models, and thus disregarded the alternative approach, quite valid in different frameworks (like forecasting). 


\subsection{A first look at the database}

Figure 1 presents, as a first illustration of the database, some details on total revenue and total expenditure. The first two figures in each panel show the smoothed and filtered estimates, not seasonally-adjusted, and the 95\% confidence bands around the estimates. The seasonallyadjusted counterparts are also displayed in the first two figures of each panel. The lower part of each panel compares visually the shape of the smoothed and the filtered estimates of the seasonally-adjusted series (levels and quarter-on-quarter growth rates). Some points are worth highlighting. Firstly, the smoothed estimates of TOR and TOE are estimated with high accuracy; this is apparent from the reduced confidence bands in both cases, which converge to zero as 1999Q1 is reached (first year of actual data). As expected, this is not the case for the filtered estimates; in fact, the confidence bands for the period 1980Q1-1999Q4 are not shown in the corresponding figures because the variance is extremely high. Nevertheless, after some 8-10 observations the filtered estimates get stabilised around a mean value. Secondly, the seasonal profile estimated in both cases differs markedly in the pre-1999 period; this is normal, taking into account that, in the case of the filtered estimate, the information regarding the seasonal profile pertains to the latter part of the sample, and the KF only internalises the future information implicitly by estimation of the parameters of the model with the full dataset. Thirdly, the latter difference almost vanishes when the seasonal component is netted-out and the seasonally-adjusted series computed with the FIS and the KF are pictured together; nevertheless, as it is apparent from the presented growth rates, the filtered series are more volatile.

Figures 2, 3 and 4 present quarter-on-quarter growth rates of all the variables (seasonallyadjusted) included in the database. Figure 2 shows total government revenue and its components, Figure 3 total government expenditure and its main components, and Figure 4 the decomposition of government consumption.

As regards the information displayed in Figure 2, the growth rates of direct taxes displays much more volatility than the aggregate of total revenues (2.4\% relative standard deviation), while social contributions and indirect taxes present a volatility similar to that of TOR $(1.2 \%$ and $1.0 \%$ relative standard deviation). The relative volatility displayed by quarterly data is similar to that present in annual data. DTX, SCT and TIN present similar shares (in 2008) of total revenue in the euro area: $27 \%, 34 \%$ and $29 \%$ of the total respectively, while the rest is account for by other government revenues (the dynamics of which are displayed in the latest chart of the figure).

In Figure 3 we show total expenditure and its components. Government consumption (GCN) and transfers to households (THN) represent the bulk of TOE, with shares (in 2008) of $43 \%$ and 
$34 \%$ respectively; the ratio of the standard deviation of GCN and THN with the standard deviation of TOE is 1.2 and 1.0 respectively. The smaller components, in turn, present much higher relative volatility with respect to the aggregate, of 4.3 for GIN (5\% weight), 3.3 for INP (6\% weight), and, particularly, of 9 for OTOE (computed as a residual and amounts to some $8 \%$ of TOE). SIN, in turn, is a small item amounting to some $3 \%$ of TOE, and with a relative standard deviation that doubles that of TOE. We also show in the figure unemployment benefits, UNB, a subcomponent amounting to some $8 \%$ of THN, and some 4 times more volatile than it.

Within government consumption, as shown in Figure 4, non-wage consumption expenditure $(\mathrm{OGCN})$ is more volatile than wage expenditure (COE), 1.8 and 0.9 in terms of relative standard deviations to GCN respectively, while both amount to some $50 \%$ of GCN.

\subsection{Basic dynamic properties of the database and comparison with existing alternatives}

To highlight the properties of the database constructed in our paper [PPP2009 henceforth], in this section we will discuss some of its dynamic properties in the framework of the two main existing alternative datasets that comprise historical quarterly fiscal data: the AWM database, initially developed by Fagan et al. (2001, 2005), ${ }^{14}$ and the dataset that accompanies the DSGE model by Forni et al. (2009). ${ }^{15}$ It is worth highlighting that we do not aim at making a systematic comparison of the alternative datasets but just to exemplify the existence of differences in the datasets.

As discussed above, the AWM database covers a wide range of quarterly euro area macroeconomic time-series. The latest update of the database covers the period 1970Q12008Q4 for most variables. The AWM database is quite thorough in the construction of quarterly historical macroeconomic data as regards aggregation practices, consistency with sources of quarterly data (mainly Eurostat) and other relevant issues. The AWM database provides also a wide array of quarterly fiscal variables. Nevertheless, fiscal variables, not being part of the core of variables provided in this source, were constructed following a different approach. In particular, annual fiscal variables as a ratio to nominal GDP are interpolated using either mechanical interpolation approaches or quarterly macroeconomic indicators (like, for example, private consumption for GDP). The AWM dataset has a history of vintages, as new member states have joined the euro area over the last few years, and also because some improvements/additions have been incorporated: we will use in this section the latest available

\footnotetext{
14 We thank José Emilio Gumiel for providing us with the different vintages of the AWM database.

15 We thank Lorenzo Forni for providing us with the variables of FMS2009 shown in this section.
} 
version (AWM2008) as well as, occasionally, the two previous versions (AWM2007, AWM2005).

As regards the database of Forni et al. (2009) [FMS2009 henceforth], it encompasses the main fiscal variables typically needed in a small-scale macroeconomic model, but it is much more limited in the number of variables covered than the AWM and PPP2009 datasets. As in the case of the AWM, annual fiscal variables are mostly interpolated on the basis of quarterly macroeconomic indicators (see their quite detailed Appendix B).

Figure 5 presents a visual comparison of the levels (not seasonally-adjusted series) and growth rates (seasonally-adjusted series) of TOR, TOE (not available for FMS2009), GCR and THN. ${ }^{16}$ Differences in the levels of the selected variables (shown as percentage differences with respect to PPP2009) are apparent from the left-hand-side panels of Figure 5, especially for the period prior to 1997. Part of these differences are due to the different definition of the euro area used (euro area 16 in AWM2008, euro area 12 in PPP2009, and so on, that can be easily account for by re-scaling), while the most important part might be due to the fact that the successive vintages of the AWM database keep data prior to 1996 as frozen, and update the new levels using growth rates (as clear from the right-hand panels of Figure 5). Some differences are thus, observable, between the levels of the different versions of the AWM database.

A comparison of quarter-on-quarter growth rates of seasonally-adjusted series is shown in the right-hand panels of Figure 5, where absolute differences in the growth rates with respect to PPP2009 are shown. Two issues are worth highlighting. Firstly, as it could be expected, growth rates of AWM vintages prior to 1996 are identical in the case of TOR, TOE and GCR. Secondly, in general quarterly absolute differences are contained between \pm 1 percentage points, while on average report similar values (differences are centred around zero).

The information shown in Table 3 complements the visual inspection discussed in the previous paragraphs. In Table 3 we show simple correlation coefficients between quarter-on-quarter growth rates of seasonally-adjusted series for the period in which all databases overlap (1980Q1-2005Q4). The correlation of PPP2009 with AWM2008 and FMS is above 0.7 in all the cases, and ranges from 0.74 in the case of TOR (AWM2008) to 0.90 in the case of THN (FMS2009). In the same fashion, the correlation of FMS2009 with AWM2008 is above 0.7 in the case of GCR (by construction) and THN, while it is somewhat lower (0.64) in the case of TOR; in fact, in the latter case, the correlations of PPP2009 and FMS2009 with AWM datasets are maximised for the AWM2005 vintage.

\footnotetext{
16 TOR and THN in FMS2009 are presented in real terms; we translated them to nominal values using the GDP deflator included in the AWM database (2008 version). AWM fiscal variables are presented as a \% of nominal GDP; thus, the levels of fiscal variables are recovered by multiplying fiscal variables as a \% of GDP times nominal (SA) GDP. THN in the AWM database is not the same as PPP2009 and FMS2009 as it comprises, on top of the ESA95 concept D62, D75 to non-profit units. GCR in FMS2009 is in line with AWM (see Appendix B in Forni et al., 2009).
} 
Thus, when considering the previous basic, correlation analysis, differences among different datasets do exist, but seem to be limited. Nevertheless, it is likely that when conducting more complicated empirical applications, most notably analyses involving dynamic issues, the results may be affected by the selection of the dataset, for the reasons reported above, linked to the presence of "endogenity biases" when using the AWM and FMS2009 datasets.

\subsection{Some stylised facts of the database}

In Table 4, we report dynamic cross-correlation functions. We look at the unconditional correlations between detrended series at the standard business cycle frequencies. Following standard practice we measure the co-movement between two series using the cross correlation function (CCF thereafter). Each row of this table displays the CCF between a given detrended fiscal variable at time $\mathrm{t}+\mathrm{k}$, and detrended GDP at time $\mathrm{t}$. We only show results for a set of standard filters ${ }^{17}$ as applied to seasonally-adjusted time series, and so the results do not have to be taken as a systematic tabulation of stylised facts, but rather as an illustration of some properties of the database.

Each row of this table displays the CCF between a measure of detrended real GDP at time $t$, and a detrended fiscal variable at time $\mathrm{t}+\mathrm{k}$. Following the standard discussion in the literature, it is said that the two variables co-move in the same direction over the cycle if the maximum value in absolute terms of the estimated correlation coefficient of the detrended series (call it dominant correlation) is positive, that they co-move in opposite directions if it is negative, and that they do not co-move if it is close to zero. A cut-off point of 0.20 roughly corresponds in our sample to the value required to reject at the $5 \%$ level of significance the null hypothesis that the population correlation coefficient is zero. Finally, the fiscal variable variable is said to be lagging (leading) the private sector variable if the maximum correlation coefficient is reached for negative (positive) values of $\mathrm{k}$.

The results in the table show the strong pro-cyclical behaviour of government revenues in the euro area, which follow the business cycle behaviour in upturns and downturns, reflecting the operation of automatic stabilisers. Total expenditure, in turn, appears pro-cyclical as well, but lagged, in line with available evidence with annual data (see Lane, 2003, Lamo et al., 2007); this behaviour is consistent with a political economy view in which the government increases spending in upturns and is forced to follow a contractionary stance in downturns to preserve fiscal sustainability. Real government consumption and social payments (THN) follows the

17 The selected filters are: (i) first difference filter; (ii) linear trend; (iii) Hodrick-Prescott filter for two alternative values of the band-pass parameter (the standard 1600, that is a fair approximation of the cycles of France and Italy, while a higher value would be more appropriate for countries with more volatile cycles like Spain, as shown by Marcet and Ravn, 2004); (iv) Band-Pass filter (with two different band-pass parameters, capturing fluctuations between 1.5 and 8 years and between 1.5 and 12 years, an observation closer to average euro area business cycle duration). 
same pattern as total government expenditure, as it would be expected given that the two items represent the main part of the aggregate. Within THN, unemployment benefits present a different pattern, given their counter-cyclical nature; unemployment-related benefits increase in downturns and decrease in upturns; UNB seem to lead real GDP by 1 or 2 quarters.

\section{Construction of a real-time database for government revenue and expenditure}

As stated in the Introduction, we provide in this Section a real-time database for aggregated total government revenue and expenditure, and thus government net lending that can be computed as the difference between the two. We construct the database for the vintages of April 2000, April and October of each year from 2001 till 2008, and April 2009. Thus, we provide time series for total revenue and total expenditure, for the period 1980Q1- till the latest quarterly figures available in each vintage.

The inputs to type (5) models are, as stated above, annual and quarterly government nonfinancial data, and monthly public accounts indicators. Data availability allow the estimation of monthly models; in order to maximize the information used for the estimation of the models, we decided to estimate monthly models rather than quarterly models for the construction of the real-time database. In any case, for the sake of comparison with the historical fiscal database, and also for simplicity of use we transform the monthly output into the quarterly frequency by summation of the three months that correspond to each quarter.

The sources of information are as follows. Vintages of annual fiscal data are taken from the successive publications of the European Commission's AMECO database, as published in real time; we used directly the electronic sources of the different versions of the AMECO database, as they were available for the period under scrutiny (for previous vintages only the paper version is available). Quarterly government finance statistics are compiled on the basis of the successive issues of the Monthly Bulletin of the ECB; the first available vintage is the August 2004 one, thus corresponding to our October 2004 vintage.

As regards monthly public accounts data, we assume that they are not revised; being recorded in cash terms, this is a more than reasonable approximation, also comparing successive vintages of data when available. The sources of cash data are displayed in Table 1; we chose Federal government total revenues and expenditures for Germany, and the Central Government measures for France, Italy and Spain already used in the construction of the quarterly historical database. Given that we take the historical cash series as indicators, we have to be careful with the assumed monthly observations available at the time of each vintage, for the monthly information to be in line with the annual and quarterly fiscal information available at each specific date. We follow the assumption of availability with a lag of two months; this 
convention is also a fair heuristic representation of average publication practices in the five euro area countries considered.

In figures 6 and 7 we present a glimpse of the real-time fiscal database. Figure 6 refers to total revenue and Figure 7 to total expenditure. In each figure, Panel A displays the evolution across vintages of quarter-on-quarter growth rates of seasonally-adjusted data for some selected dates separated by eight years (1980Q4, 1988Q4, 1996Q4) and four years (2000Q4, 2004Q4, 2007Q4). Panel B, in turn, presents averages over four years of quarter-on-quarter growth rates of seasonally-adjusted series across vintages, and also the simple correlation coefficient of each vintage of the real-time database with the estimated series in the historical quarterly fiscal database. Panel C presents the same statistics of Panel B, but for year-on-year growth rates on not seasonally adjusted data.

The main messages from figures 6 and 7 are the following. Firstly, when inspecting the evolution of selected quarterly growth rates across vintages (Panel A in each figure), some (small) differences are visible in general, while they are more substantial for the observations pertaining to the part of the sample in which quarterly ESA95 fiscal figures are available; this is the case in particular as regards the first vintage in which quarterly figures were made available (vintage Oct04), but also in subsequent publications of quarterly figures. Secondly, average growth rates of (q-on-q) seasonally-adjusted data (Panel B in each figure) are in general quite stable across vintages. Thirdly, the (contemporaneous) correlation of the time series estimated in real-time with the corresponding series in the historical quarterly fiscal database are, as it could be expected, quite high (lower part of panels $\mathrm{B}$ and $\mathrm{C}$ in each figure); correlations are lower for vintages that do not include quarterly government finance statistics data (those prior to Oct04), and higher as one moves to the latest vintages (Oct08 and Apr09 incorporate an information set quite similar to that of the historical database). Finally, average growth rates of (y-on-y) nonseasonally-adjusted data (Panel $\mathrm{C}$ in each figure) are also quite stable across vintages, displaying a small change as of the Oct04 vintage; this is reasonable, given that non-seasonally quarterly government ESA95 figures are an input to the model as of the Oct04 vintage, while before that date only annual ESA95 figures are included.

\section{Conclusions}

We construct a quarterly fiscal database for the euro area for the period 1980-2008, solely based on intra-annual fiscal information, on the basis of multivariate, state-space mixed-frequencies models. We provide a quite disaggregated set of nominal fiscal variables for the General Government sector in ESA95 terms. We also provide a real-time database for a subset of variables for bi-annual vintages covering the euro area period. 
The main features of our analysis are: (i) we provide seasonally and non-seasonally adjusted series, which are consistently and jointly estimated within our models; (ii) while following an indicator-based approach, we make use of direct fiscal information from basic sources (public accounts' data) and guarantee full coherence of interpolated and official annual and quarterly (when available) series; (iii) most importantly, our database makes use of only intra-annual fiscal information, thus allowing us to capture genuine intra-annual "fiscal" dynamics in the data. With regard to this latter point, it is worth mentioning that we avoid the problem that arises from interpolation approaches of fiscal data based on general macroeconomic indicators. Although fiscal variables may be endogenous to GDP or any other relevant tax/spending bases, the relationships between these variables are, at most, indirect and in addition they are difficult to estimate.

The fiscal databases developed in this paper (baseline database and real-time database) present the potential of constituting a useful input for broader macroeconomic analyses using euro area data and involving the use of fiscal variables, exercise currently conducted either with annual data or with limited availability of quarterly fiscal information. Studies of this type that have recently received renewed attention include simulation exercises to assess the impact fiscal stimulus packages, analyses of the interaction between monetary and fiscal policies, or the estimation of fiscal policy rules.

\section{References}

Anderson, H., M. Dungey, D. R. Osborn and F. Vahid (2007), "Constructing historical euro area data”, CAMA Working Papers 2007-18, Australian National University, Centre for Applied Macroeconomic Analysis.

Beyer, A., J. A. Doornok and D. F. Hendry (2001), "Constructing historical euro-zone data", The Economic Journal, 111, 102-121.

Bosker, E.M. (2006), "On the aggregation of eurozone data", Economics Letters, 90, 260-265.

Brüggemann, R. and Lütkepohl, H. (2006), “A Small Monetary System for the Euro Area Based on German Data”, Journal of Applied Econometrics, 21, 683 - 702.

Bryson A. E. Jr. and Y. C. Ho (1969), Applied optimal control: optimization, estimation, and control, Waltham, MA: Blaisdell.

Cimadomo, J. (2008), "Fiscal policy in real-time”, ECB Working Paper 919.

Coenen, G., K. Christoffel and A. Warne (2008), “The New Area-Wide Model of the Euro Area: A Micro-Founded Open-Economy Model for Forecasting and Policy Analysis”, ECB Working Paper No. 944.

Croushore, D. and T. Stark (2001), "A real-time data set for macroeconomists", Journal of Econometrics, 105, 111-130. 
Croushore, D. and T. Stark (2003), “A Real-Time Data Set for Macroeconomists: Does the Data Vintage Matter?", The Review of Economics and Statistics, 85, 605-617.

Croushore, D. and C. L. Evans (2006), "Data Revisions and the Identification of Monetary Policy Shocks", Journal of Monetary Economics 53, 1135-1160.

Duisenberg, W.F. (2003), "Monetary and fiscal policy in the euro area", Introduction at the International Monetary Conference, Berlin, 3 June 2003. Downloadable from http://www.ecb.int/key/03/sp030603.html.

European Central Bank (2004), "Properties and Use of General Government Quarterly Accounts”, ECB Monthly Bulletin, August issue.

European Central Bank (2008), "One monetary and many fiscal policies: ensuring a smooth functioning of EMU", ECB Monthly Bulletin, July issue.

European Central Bank (2009), ECB Monthly Bulletin, September issue, Section 5 (Boxes 9 and 10), pp. 81-89.

European Commission (2002a), Reg. (EC) No 1221/2002 of the European Parliament and of the Council of 10 June 2002 on quarterly non-financial accounts for general government.

European Commission (2002b), "ESA95 manual on government deficit and debt, Methods and Nomenclatures series", European Commission, Luxembourg.

European Commission (2006), "Manual on quarterly non-financial accounts for general government", European Commission, Luxembourg. http://epp.eurostat.ec.europa.eu/cache/ ITY_SDDS/Annexes/gov_q_ggnfa_esms_an7.pdf

European Commission (2007). Quarterly government accounts and fiscal surveillance, pp 103106 in "Public Finances in EMU", European Commission, Brussels.

European Commission (2009), "Public Finances in EMU", European Economy 5/2009, European Commission, Brussels.

Fagan, G., J. Henry and R. Mestre (2001), "An area-wide model (AWM) for the euro area", European Central Bank Working Paper Series, 42, January.

Fagan, G., J. Henry and R. Mestre (2005), "An area-wide model (AWM) for the euro area", Economic Modelling, 22, 39-59.

Forni, L., L. Monteforte and L. Sessa (2009), "The general equilibrium effects of fiscal policy: estimates for the euro area", Journal of Public Economics, 93, 559-585.

Giannone, D., J. Henry, M. Lalik and M. Modugno (2006), "An Area-Wide Real Time Database for the Euro-Area”, presentation at the LINK meeting, Geneva 31.10.2006. Available at www.chass.utoronto.ca/link/meeting/papers/1031_pm_henry.pdf

Harvey, A. (1989), "Forecasting Structural Time Series Models and the Kalman Filter". Cambridge University Press.

Harvey, A.C. and Chung, C.H. (2000), "Estimating the underlying change in unemployment in the UK". Journal of the Royal Statistics Society, Series A, 163, 303-339. 
Kalman, R. E. (1960), “A new approach to linear filtering and prediction problems”, Journal of Basic Engineering, 82, 35-45.

Kalman, R. E and R. S. Bucy (1961), "New Results in Linear Filtering and Prediction Theory", 83, 95-108.

Lamo, A., J. J. Pérez and L. Schuknecht (2007), "The cyclicality of consumption, wages and employment of the public sector in the euro area", ECB WP \#757.

Lane, P. (2003), “The cyclical behaviour of fiscal policy: evidence from the OECD”, Journal of Public Economics, 87, 2661-2675.

Leal, T., Pérez, J.J., Tujula, M. and Vidal J.P. (2008), "Fiscal forecasting: lessons from the literature and challenges", Fiscal Studies 29, 347-386.

Giordano, R. S. Momigliano, S. Neri and R. Perotti (2007), “The effects of fiscal policy in Italy: evidence from a VAR model", European Journal of Political Economy, 23, 707-733.

Gómez, V. and A. Maravall (1998), “Automatic modeling methods for univariate series”, Banco de España, Documento de Trabajo n. 9808.

Gómez, V. and A. Maravall (1996), "Programs TRAMO (Time series Regression with Arima noise, Missing observations, and Outliers) and SEATS (Signal Extraction in Arima Time Series). Instructions for the User", Working Paper 9628, Banco de España.

Marcet, A. and M. Ravn (2004), "The HP-filter in cross-country comparisons", CEPR DP 4244.

Moauro F. and Savio G. (2005), “Temporal Disaggregation Using Multivariate Structural Time Series Models". Econometrics Journal, 8, 214-234.

Morris, R., C. R. Bras, F. de Castro, S. Jonk, J. Kremer, S. Linehan, M. R. Marino, C. Schalck and O. Tkacevs (2009), "Explaining government revenue windfalls and shortfalls: an analysis for selected EU countries", to appear, Working Paper Series of the ECB.

Morris, R. and L. Schuknecht (2007), "Structural balances and revenue windfalls - the role of asset prices revisited", ECB Working Paper No 737.

Onorante, L., Pedregal, D.J., Pérez, J.J. and Signorini, S. (2009), "The usefulness of infraannual government cash budgetary data for fiscal forecasting in the euro area", forthcoming in Journal of Policy Modeling.

Orphanides, A. (2001), "Monetary Policy Rules Based on Real-Time Data", American Economic Review, 91, 964-985.

Pedregal, D. J. and Pérez, J. J. (2009), "Should quarterly government finance statistics be used for fiscal surveillance in Europe?”, forthcoming in International Journal of Forecasting.

Pedregal, D. J. and P. C. Young (2002), "Statistical Approaches to Modelling and Forecasting Time Series". In Clements, M. and D. Hendry (eds.), Companion to Economic Forecasting, 69-104. Blackwell Publishers: Oxford. 
Pérez, J. J. (2007), "Leading Indicators for Euro Area Government Deficits", International Journal of Forecasting 23, 259-275.

Pérez, J. J. and A. J. Sánchez (2009), "Is there a signalling role for public wages? Evidence for the euro area based on macro data", Bank of Spain, mimeo, July.

Proietti T. and Moauro F. (2006), "Dynamic Factor Analysis with Nonlinear Temporal Aggregation Constraints". Journal of the Royal Statistical Society, series C (Applied Statistics), 55, 281-300.

Ratto, M., W. Roeger, and J. in't Veld (2009), “Quest III, An estimated open-economy DSGE model of the Eurozone with fiscal and monetary policy". Economic Modelling, 26, 222-233.

Silvestrini A., Salto M. , Moulin L., and Veredas D. (2008), "Monitoring and forecasting annual public finance deficit every month: the case of France". Empirical Economics, 34, 493-524.

Smets, F. and R. Wouters (2003), "An estimated Dynamic Stochastic General Equilibrium model of the euro area", Journal of the European Economic Association, 1, 1123-1175.

West, M. and J. Harrison (1989), Bayesian Forecasting and Dynamic Models, New York: Springer-Verlag.

Young, P. C. and D. J. Pedregal (1999), "Recursive and En-Block approaches to signal extraction", Journal of Applied Statistics, 26, 103-128. 


\section{Appendix A. Filtering vs. smoothing}

Two simple simulations would illustrate the improvement of smoothed estimates over filtered ones. The first simulation consists of 5,000 runs of 1,000 data points of a random walk plus noise model in equation (A1).

$$
\mathrm{z}_{\mathrm{t}}=\frac{\mathrm{w}_{\mathrm{t}}}{(1-\mathrm{B})}+\mathrm{v}_{\mathrm{t}}
$$

with $\sigma_{\mathrm{w}}^{2} / \sigma_{\mathrm{v}}^{2}=1$ (top left panel of Figure A shows one example). Several artificial missing values are generated from samples 700 to 720 . The absolute errors of smoothed and filtered estimates for the missing values are computed for the 5,000 simulations and the mean behaviour is shown in Figure A (top right panel).

The second simulation consists of 5,000 runs of the same model in which an artificial positive jump is included in sample 700 and 20 observations just after such jump are set to missing values (701 to 720). Results, both assuming the position of the jump known (bottom left) and unknown (bottom right) are also shown in Figure A.

Figure A: Filtering vs smooting? Simulation results: top-left, one run of simulation in equation (A1); top-right, Mean Absolute Errors of 5,000 runs over the missing gap; bottom-left, MAE with an artificial jump added and estimated; bottom-right, MAE of last, but ignoring the existence of jump.
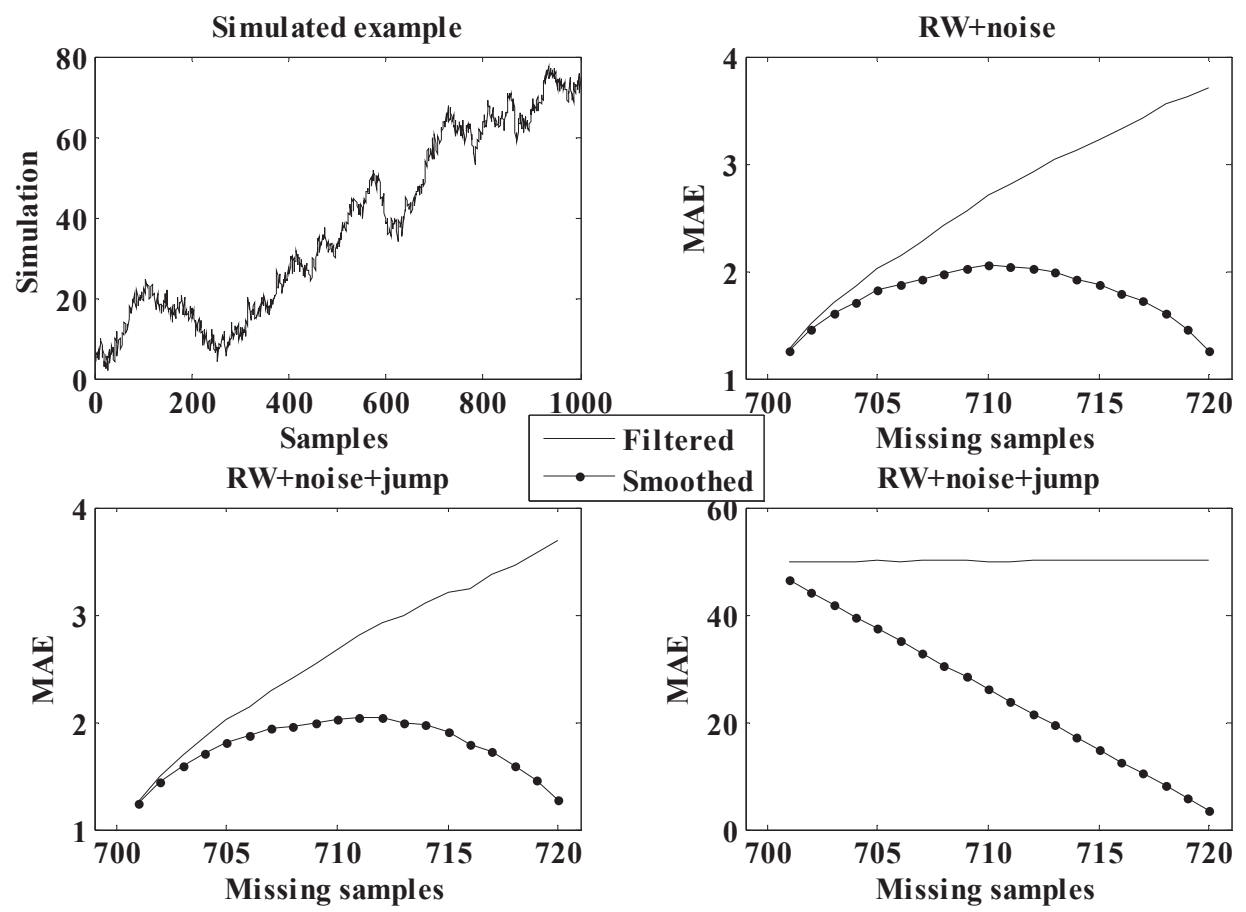

Conclusions from Figure A are clear: using smoothed estimates as the reconstruction of the missing values produce closer observations to the true values than the filtered ones. Filtered estimates error always increase along the missing gap because the algorithm looks backwards 
and the available information is far away as the algorithm proceeds forward. However, since the smoother algorithm takes into account information at both ends of the missing gap, the errors are minimum at both extremes and maximum at the centre, where the true information is far away. Something not shown on the figure is that as the ratio $\sigma_{\mathrm{w}}^{2} / \sigma_{\mathrm{v}}^{2}$ decreases, i.e. as the signal to noise ratio decreases, the advantages of smoothed estimates tend to disappear, but it is never worse than the filtered counterparts.

\section{Appendix B. The construction of the database variable by variable}

Total government revenue (TOR). Total government revenue is interpolated directly rather than computed on the basis of its subcomponents, as there is more information available for the aggregate than for the components. In this case $\left\{\mathbf{u}_{t}\right\}$ contains a total revenue variable for the five countries considered at the quarterly frequency, referred to the General Government sector for the period 1980-2008 in the cases of Germany (cash concept) and the Central Government sector for France (cash, 1980-2008), Italy (cash, 1980-2008), the Netherlands (cash, 1980-2008) and Spain (ESA, 1984-2008).

Given the wealth of available variables in the case of TOR, it is also possible to estimate a model at the monthly frequency with good quality data input, in order to check the obtained estimates. In this case, Federal/Central government indicators are available for the five considered countries for the period starting in January 1980 (January 1984 in the case of Spain).

Direct taxes (DTX). In the case of direct taxes it was necessary to resort to quarterly ESA95 data to build up country variables, and to estimate a model with an unbalanced dataset, i.e. with missing values for three countries in matrix $\left\{\mathbf{u}_{\mathrm{t}}\right\}$ (Italy, Netherlands, and to a lesser extent Spain). In the cases of Italy and the Netherlands the intra-annual information used is quarterly ESA95 data for the period 1991Q1-2008Q4 for the general government. In the case of France it was possible to reconstruct a homogeneous quarterly time series for the general government sector in ESA terms for 1980-2008, resorting to the Eurostat database (for the period from 1991 on) backcasted (using growth rates) with the same general government series extracted from the BIS database (period before 1991). In the cases of Germany and Spain, information for the Federal/Central government covering the periods 1980Q1-2008Q4 and 1984Q1-2008Q4 respectively, was used to backcast, by means of model (5), consistent ESA quarterly series make up of quarterly (for the periods 1991 onwards and 1995 onwards, respectively) and annual information (for the period 1980-1990 and 1980-1994, respectively).

The decomposition of DTX into direct taxes paid by corporations (DTE) and direct taxes paid by households (DTH) is done in a rather mechanical way, given the absence of direct quarterly information for the two sub items. Each quarterly DTX figure is distributed into the 
corresponding DTE and DTH quarterly figures using the weights obtained from annual proportions. Thus, a quarterly DTX observation is allocated to a quarterly DTE figure by weighting the corresponding quarterly DTX observation by the fraction of DTE over DTX in the year to which that quarter belongs to. Then, the quarterly figure for DTH is computed as a residual: DTH $=$ DTX - DTE.

Social security contributions (SCT). For Social Security Contributions we were only able to find data for Germany, France and Spain, thus $\left\{\mathbf{u}_{t}\right\}$ includes only three variables in this case. In the case of France we build up a homogeneous quarterly time series for the general government sector in ESA terms for 1980-2008, using to the Eurostat database (data for 1991-2008) backcast (using growth rates) with an analogous series extracted from the BIS database (period 1980-1990). As regards Germany, available information regarding social contributions is taken from the BIS database to interpolate, by means of model (5), consistent ESA series make up of quarterly (for the periods 1991 onwards) and annual information (for the period 1980-1990). The same procedure was applied with Spanish series, but in this case the indicator variable used was total social security contributions received by the Social Security System.

The decomposition of SCT into employer's social contributions (SCR) and other social contributions (SCE) is also done in a fairly mechanical way, as in the case of direct taxes. It is worth noticing that SCE includes contributions paid by employees, but also contributions paid by self-employed and other. It is also worth mentioning that the breakdown is only provided for the period 1991Q1-2008Q4, the only period for which we found consistent information.

Indirect taxes (TIN). In the cases of Germany, Italy, Spain and the Netherlands information on "indirect taxes less subsidies" as provided by national accounts, covering the period 1980Q12008Q4, was used to backcast, by means of model (5), consistent country ESA series make up of quarterly (for the periods 1991 onwards, 1995 onwards in the case of Spain) and annual information (for the remaining periods). In the country models we included, in addition, direct information on indirect taxes for the Federal/Central governments, as available from the cash accounts of the governments. In the case of France it was possible to reconstruct a homogeneous quarterly time series for the general government sector in ESA terms for 19802008 , as discussed above.

Other revenues (OTOR). The item "Other government revenues" is computed as a residual as OTOR $=$ TOR - DTX - SCT - TIN. This variable accounts for some $10 \%$ of total revenue, and includes national accounts items such as "sales", "capital revenue", and "other current transfers receivable", that includes in turn, among other items, net receipts received by the euro area general government from the EU Budget and interest receivable. 
Total government expenditure (TOE). Total government expenditure is interpolated directly. In this case $\left\{\mathbf{u}_{t}\right\}$ contains a total expenditure variable for the five countries considered, referred to the General Government sector for the period 1980-2008 in the cases of Germany (cash concept), and the Central Government sector for France (cash, 1980-2008), Italy (cash, 19802008), the Netherlands (cash, 1980-2008) and Spain (ESA, 1984-2008).

As in the case of TOR, it is also possible to estimate a model at the monthly frequency with good quality data input, as check, given data availability. In this case, Federal/Central government indicators are available for the five considered countries for the period starting in January 1980 (January 1984 in the case of Spain).

Final consumption of the General Government (GCN, GCR). Non-seasonally and seasonally adjusted real and nominal government consumption variables are based on available raw information from Eurostat (ESA95 database). In the case of the real variables, homogeneous series in the ESA95 database for Germany (available for the period 1991Q1 onwards), Spain (1995Q1 onwards) and Italy (1981Q1 onwards) are backcasted using growth rates of available real government consumption series in former definitions (ESA79, West Germany in the case of Germany). The series for France and the Netherlands are available for the period 1980Q12008Q4 in the ESA95 database. In the case of GCN the series were available for all countries for the period 1980Q1-2008Q4 in the ESA95 database, with the exception of Germany, in which case it was necessary to join West German and Unified German series, following the usual procedure.

Government wage consumption expenditure (COE). For France, it was possible to reconstruct a homogeneous COE quarterly time series for the general government sector in ESA terms for 1980-2008, as in the cases discussed above. The figures of Giordano et al. (2007) are used in conjunction with the available official data to build up consistent general government series for 1982Q1-2008Q4 for Italy. In the case of Germany and Spain we used available Federal/Central government variables of personnel expenditure to interpolate the available (annual-quarterly) government finance statistics' series. In the euro area, COE represents some $50 \%$ of GCN.

Government no-wage consumption expenditure (OGCN). Government non-wage consumption expenditure is computed as a residual as the difference of final consumption expenditure (GCN) and compensation of employees (COE). Thus, it includes not only government purchases (intermediate consumption), but also "Social transfers in kind provided via non government units", "Consumption of fixed capital", (negative) "Sales", "Taxes on production paid minus subsidies received" and "Net operating surplus". The latter two items are residual, while, in the euro area, intermediate consumption represents some $25 \%$ of total government consumption, approximately the same fraction as "Social transfers in kind provided via non government units" 
Government employment ( $L G N)$. EU member states do not report to Eurostat standardized annual employment figures for the general government sector. Thus, in this case it is necessary to resort to other sources. As discussed in Pérez and Sánchez (2009), we use annual OECD as an anchor for the euro area aggregate. As regards quarterly information, the available source covering a wider time span can be found in Eurostat's ESA95 figures on "Employment in other services", mainly non-market services, the bulk of which are related to government activities. We take data from this source for the period 1980Q1 onwards for Germany, Spain and Italy, for the period starting in 1990Q1 for France and for the period 1987Q1 onwards for the Netherlands. As an additional indicator we used our estimated measurer of euro area GCR, given that government consumption in real terms should contain information of changes in government employment underlying COE.

Government investment. For France and the Netherlands, it was possible to reconstruct homogeneous GIN quarterly time series for the general government sector in ESA terms for 1980-2008, as in the cases discussed above. In the case of Italy, the figures of Giordano et al. (2007) are used in conjunction with the available official data to build up consistent general government series for 1982Q1-2008Q4. As regards Germany and Spain we use available Federal/Central government variables to interpolate the available (annual-quarterly) government finance statistics' series.

Interest payments (INP). In the case of Germany and Spain we use available Federal/Central government variables of interest expenditure to interpolate the available (annual-quarterly) government finance statistics' series. For France, it was possible to reconstruct a homogeneous INP quarterly time series for the general government sector in ESA terms for 1980-2008, as in the cases discussed above. The figures of Giordano et al. (2007) are used in conjunction with the available official data to build up consistent general government series for 1982Q1-2008Q4 for Italy.

Subsidies (SIN). In order to obtain a quarterly series for SIN for the whole period 1980-2008 we proceed in two steps. In a first step, we used national accounts euro area "indirect taxes less subsidies" data (available for the period 1991Q1 onwards) and interpolated the period for which only annual data is available using model (5) and as indicators quarterly "indirect taxes less subsidies" as provided by national accounts for the five countries considered (for the period 1980-2008). The so constructed variable, was then subtracted from TIN (as computed above) in order to produce a measure of "Subsidies", call it SIN*.

SIN* is not yet a perfect measure to be taken for our variable "Subsidies", given that the concept of "indirect taxes less subsidies" included in the standard national accounts database does include net indirect taxes paid to EU institutions and net subsidies received from EU 
institutions, while these are excluded from the accounts of the general government. This is due to the fact that funds to and from EU institutions are allocated to the accounts of the "rest of the world" in the accounts of the sectors. Thus, in a second step we used SIN* as an indicator to interpolate SIN.

Social payments (THN) and unemployment benefits (UNB). By the item "Social payments" we refer to the national accounts concept D.62, i.e. social transfers no including "Social transfers in kind provided via non government units" (D.6311+D.63121+D.63131) that are instead included in government consumption, as discussed above. The variable THN ${ }^{*}=$ TOE - SIN - INP GCN - GIN, that is, total expenditure excluding government consumption, government investment, interest payments and subsidies, should be a fair proxy of social payments. Indeed, for the euro area, the ratio of annual ESA THN and THN* in levels is equal to 1.08 on average for the period 1995-2008. Thus, given the absence of other intra-annual information of help, we use as indicator of euro area THN the derived quarterly variable THN*. We estimate a model of type (5) in which $\left\{\mathrm{z}_{\mathrm{t}}\right\}$ is THN, and $\left\{\mathbf{u}_{\mathrm{t}}\right\}$ is THN*.

A relevant subcomponent of social payments is unemployment benefits (COFOG 10.5.0 category). This is a variable that appears in numerous macroeconomic models and thus we decided to provide an estimate for it. For UNB, we use as quarterly indicator quarterly euro area THN (as computed in the previous step).

Other expenditure (OTOE). The item "Other government expenditure" is computed as a residual as $\mathrm{OTOE}=\mathrm{TOE}-\mathrm{THN}-\mathrm{INP}-\mathrm{SIN}-\mathrm{GCN}-\mathrm{GIN}$. This variable accounts for some $7 \%$ of total expenditure. It includes the following main items: "other current transfers payable" (that includes small items like payments to the EU Budget), "other net acquisitions of non-financial assets" and "capital transfers".

\section{Appendix C. Structure and contents of the databases}

Quarterly fiscal database. It is provided in MsExcel format (file: EA_Qfiscal_PPP2009_DATABASE.xls) and comprises four worksheets: (i)

DATABASE_FIS_non-SA: smoothed non-seasonally adjusted series in columns; (ii) DATABASE_FIS_SA: smoothed seasonally adjusted series in columns; (iii) DATABASE_KF_non-SA: filtered non-seasonally adjusted series in columns; (iv) DATABASE_KF_SA: filtered seasonally adjusted series in columns.

Real-time quarterly fiscal database. It is also provided in MsExcel format (file: EA_Qfiscal_PPP2009_Real-time-database.xls) and comprises eight worksheets: (i) RTD_TOR_FIS: smoothed non-seasonally adjusted series in columns (total government 
revenue, TOR); (ii) RTD_TOR_FIS_SA: smoothed seasonally adjusted series in columns (TOR); (iii) RTD_TOR_KF: filtered non-seasonally adjusted series in columns (TOR); (iv) RTD_TOR_KF_SA: filtered seasonally adjusted series in columns (TOR); (v) RTD_TOE_FIS: smoothed non-seasonally adjusted series in columns (total government expenditure, TOE); (ii) RTD_TOE_FIS_SA: smoothed seasonally adjusted series in columns (TOE); (iii) RTD_TOE_KF: filtered non-seasonally adjusted series in columns (TOE); (iv) RTD_TOE_KF_SA: filtered seasonally adjusted series in columns (TOE). 


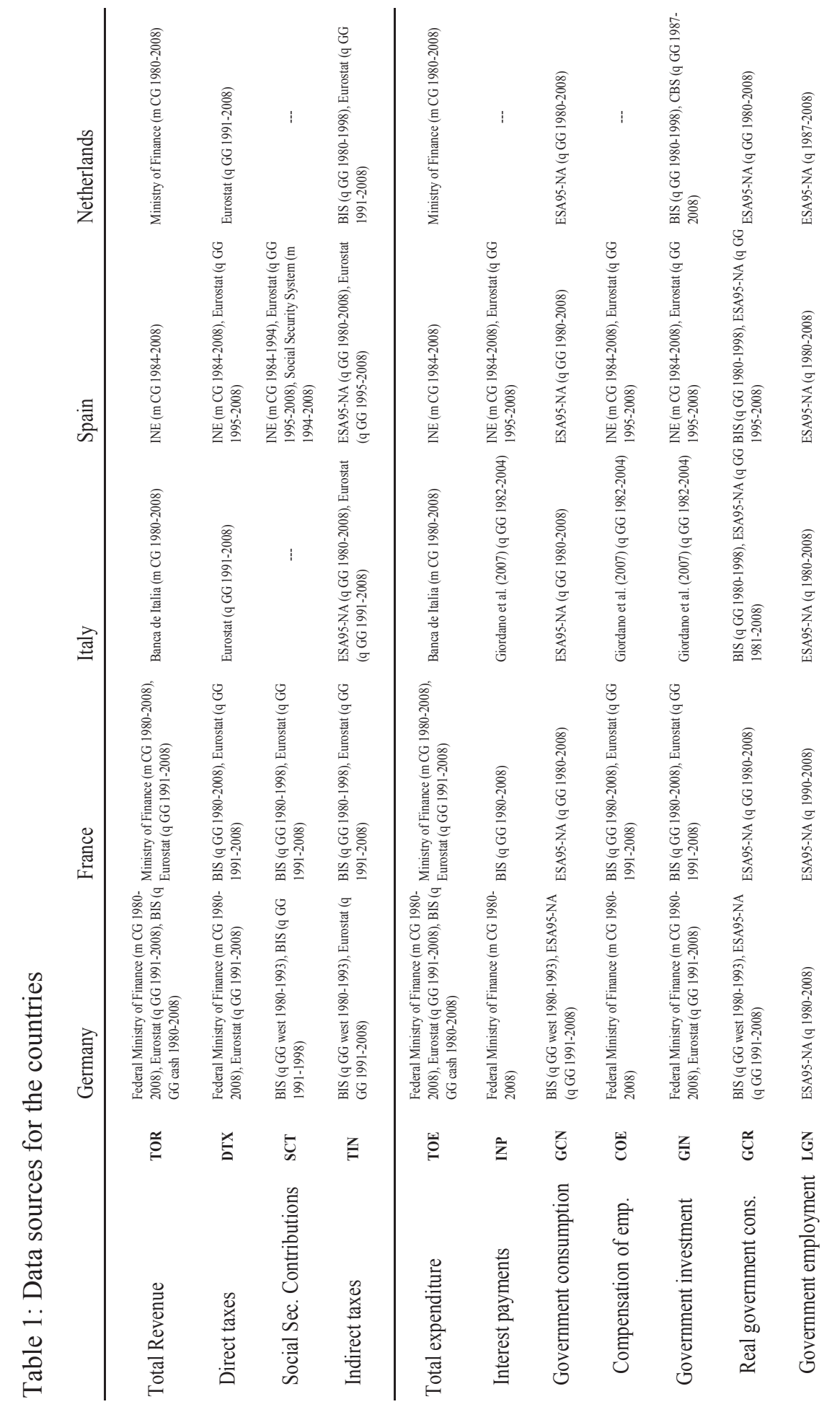


Table 2: The structure of the quarterly fiscal database

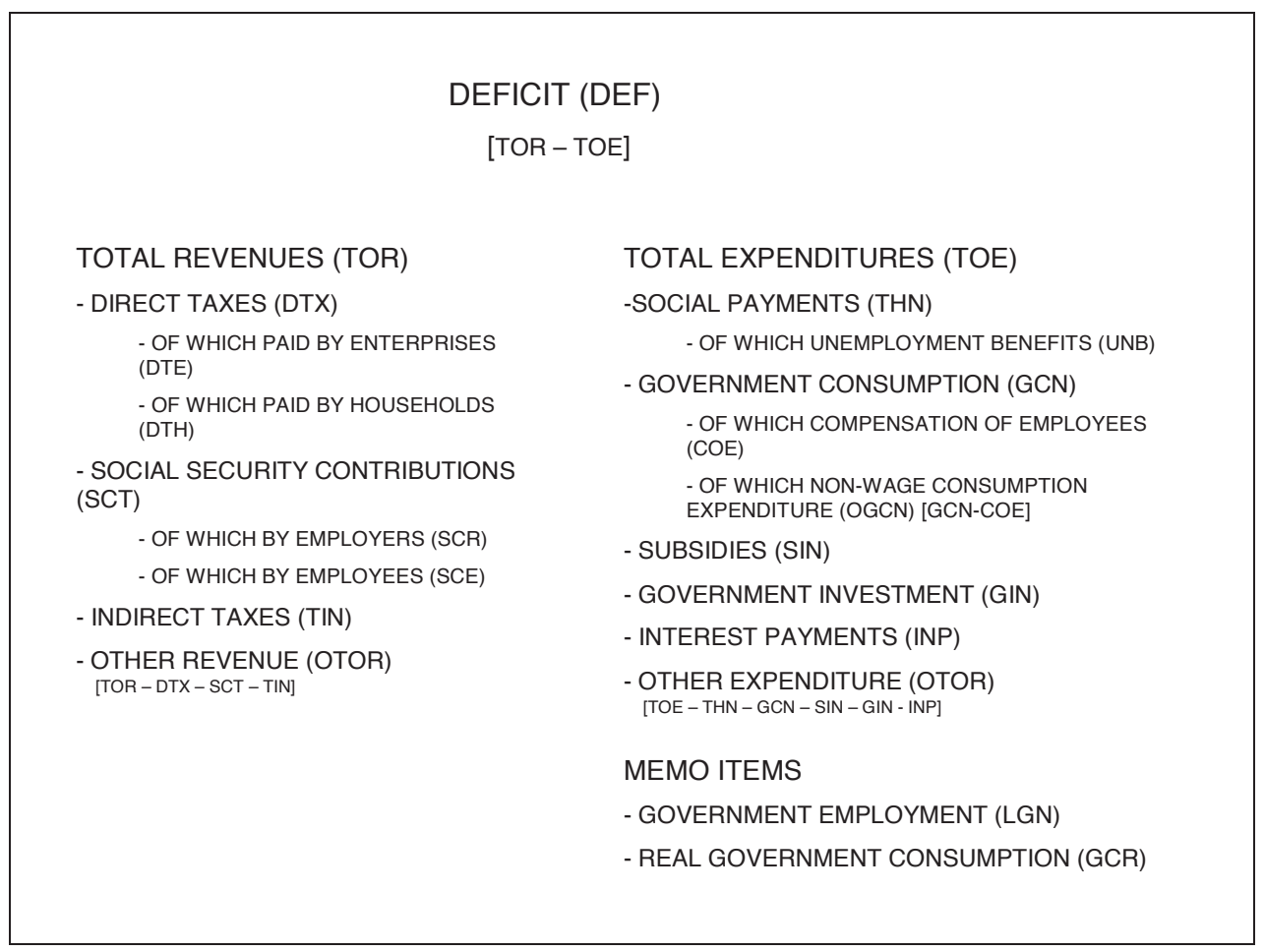

Table 3. Correlation coefficients (quarter-on-quarter growth rates of seasonally-adjusted series): quarterly database, AWM and database by Forni et al. (2009). Sample 1980Q1-2005Q4.

\begin{tabular}{|c|c|c|c|c|c|}
\hline TOR & AWM_2008 & AWM_2007 & AWM_2005 & FMS2009 & PPP2009 \\
\hline AWM_2008 & 1.00 & & & & \\
\hline AWM_2007 & 0.94 & 1.00 & & & \\
\hline AWM_2005 & 0.85 & 0.84 & 1.00 & & \\
\hline FMS2009 & 0.64 & 0.65 & 0.81 & 1.00 & \\
\hline PPP2009 & 0.74 & 0.72 & 0.82 & 0.76 & 1.00 \\
\hline TOE & AWM_2008 & AWM_2007 & AWM_2005 & FMM2009 & PPP2009 \\
\hline AWM_2008 & 1.00 & & & & \\
\hline AWM_2007 & 0.95 & 1.00 & & & \\
\hline FMS2009 & 0.90 & 0.95 & 1.00 & & \\
\hline FMM2009 & - & - & - & 1.00 & \\
\hline PPP2009 & 0.83 & 0.84 & 0.85 & - & 1.00 \\
\hline GCR & AWM_2008 & AWM_2007 & AWM_2005 & FMS2009 & PPP2009 \\
\hline AWM_2008 & 1.00 & & & & \\
\hline AWM_2007 & 0.99 & 1.00 & & & \\
\hline AWM_2005 & 0.97 & 0.98 & 1.00 & & \\
\hline FMS2009 & 0.97 & 0.98 & 0.98 & 1.00 & \\
\hline PPP2009 & 0.80 & 0.79 & 0.78 & 0.80 & 1.00 \\
\hline THN & AWM_2008 & AWM_2007 & AWM_2005 & FMS2009 & PPP2009 \\
\hline AWM_2008 & 1.00 & & & & \\
\hline AWM_2007 & 0.56 & 1.00 & & & \\
\hline AWM_2005 & 0.49 & 0.40 & 1.00 & & \\
\hline FMS2009 & 0.76 & 0.53 & 0.44 & 1.00 & \\
\hline PPP2009 & 0.80 & 0.53 & 0.42 & 0.90 & 1.00 \\
\hline
\end{tabular}


Table 4. Some stylised facts computed on the basis of the quarterly fiscal database. Sample 1980Q1-2008Q4. Quarterly real GDP and GDP deflator are taken from the AWM database.

\begin{tabular}{|c|c|c|c|c|c|c|c|c|c|c|c|c|c|c|c|}
\hline \multirow[b]{2}{*}{ TOR } & \multicolumn{14}{|c|}{$\operatorname{CCF}\left(\mathrm{GDP}_{\mathrm{t}}\right.$, fiscal $\left._{\mathrm{t}+\mathrm{k}}\right)$} & \\
\hline & $\begin{array}{c}\text { relative } \\
\text { std }\end{array}$ & -6 & -5 & -4 & -3 & -2 & -1 & 0 & 1 & 2 & 3 & 4 & 5 & 6 & \\
\hline First diff filter & 1.37 & 0.11 & 0.17 & 0.21 & 0.18 & 0.20 & 0.20 & 0.43 & 0.34 & 0.19 & 0.28 & 0.19 & 0.15 & 0.18 & pro-cyclical contemp \\
\hline Linear trend & 1.53 & 0.23 & 0.35 & 0.47 & 0.56 & 0.65 & 0.72 & 0.78 & 0.79 & 0.77 & 0.73 & 0.67 & 0.60 & 0.52 & pro-cyclical lagged \\
\hline HP 1600 & 1.68 & 0.10 & 0.24 & 0.35 & 0.44 & 0.52 & 0.59 & 0.66 & 0.64 & 0.59 & 0.54 & 0.46 & 0.36 & 0.28 & pro-cyclical contemp \\
\hline HP 3200 & 1.43 & 0.21 & 0.34 & 0.46 & 0.54 & 0.62 & 0.69 & 0.75 & 0.73 & 0.69 & 0.64 & 0.56 & 0.47 & 0.37 & pro-cyclical contemp \\
\hline BP $(1,5,8$ years $)$ & 2.11 & 0.01 & 0.16 & 0.29 & 0.41 & 0.52 & 0.61 & 0.65 & 0.63 & 0.57 & 0.49 & 0.40 & 0.30 & 0.18 & pro-cyclical contemp \\
\hline $\mathrm{BP}(1,5,12$ years $)$ & 1.64 & 0.26 & 0.41 & 0.53 & 0.64 & 0.73 & 0.80 & 0.82 & 0.81 & 0.76 & 0.69 & 0.60 & 0.49 & 0.37 & pro-cyclical contemp \\
\hline Average & 1.63 & 0.15 & 0.28 & 0.39 & 0.46 & 0.54 & 0.60 & 0.68 & 0.66 & 0.60 & 0.56 & 0.48 & 0.40 & 0.32 & pro-cyclical contemp \\
\hline TOE & $\begin{array}{c}\text { relative } \\
\text { std }\end{array}$ & -6 & -5 & -4 & -3 & -2 & -1 & 0 & 1 & 2 & 3 & 4 & 5 & 6 & \\
\hline First diff filter & 0.82 & -0.02 & -0.03 & -0.07 & -0.09 & -0.02 & -0.08 & 0.12 & 0.14 & 0.20 & 0.39 & 0.34 & 0.36 & 0.34 & pro-cyclical lagged \\
\hline Linear trend & 1.88 & -0.27 & -0.16 & -0.06 & 0.05 & 0.17 & 0.29 & 0.41 & 0.51 & 0.60 & 0.67 & 0.72 & 0.75 & 0.76 & pro-cyclical lagged \\
\hline HP 1600 & 1.15 & -0.45 & -0.38 & -0.32 & -0.25 & -0.15 & -0.03 & 0.13 & 0.29 & 0.44 & 0.57 & 0.64 & 0.67 & 0.65 & pro-cyclical lagged \\
\hline HP 3200 & 1.15 & -0.47 & -0.38 & -0.29 & -0.19 & -0.07 & 0.06 & 0.21 & 0.35 & 0.49 & 0.61 & 0.69 & 0.73 & 0.74 & pro-cyclical lagged \\
\hline $\mathrm{BP}(1,5,8$ years $)$ & 1.05 & -0.34 & -0.30 & -0.25 & -0.20 & -0.12 & 0.00 & 0.17 & 0.35 & 0.50 & 0.60 & 0.65 & 0.63 & 0.56 & pro-cyclical lagged \\
\hline $\mathrm{BP}(1,5,12$ years $)$ & 1.02 & -0.64 & -0.56 & -0.47 & -0.37 & -0.24 & -0.10 & 0.06 & 0.23 & 0.39 & 0.53 & 0.64 & 0.71 & 0.75 & pro-cyclical lagged \\
\hline Average & 1.18 & -0.37 & -0.30 & -0.24 & -0.18 & -0.07 & 0.02 & 0.18 & 0.31 & 0.44 & 0.56 & 0.61 & 0.64 & 0.63 & pro-cyclical lagged \\
\hline GCR & $\begin{array}{c}\text { relative } \\
\text { std }\end{array}$ & -6 & -5 & -4 & -3 & -2 & -1 & 0 & 1 & 2 & 3 & 4 & 5 & 6 & \\
\hline First diff filter & 1.80 & -0.03 & -0.12 & -0.04 & -0.04 & -0.04 & -0.05 & 0.12 & -0.08 & -0.01 & -0.03 & 0.17 & -0.03 & 0.10 & weak, pro-cyclical lagged \\
\hline Linear trend & 0.38 & 0.09 & 0.09 & 0.11 & 0.14 & 0.17 & 0.20 & 0.23 & 0.27 & 0.30 & 0.30 & 0.35 & 0.32 & 0.33 & pro-cyclical lagged \\
\hline HP 1600 & 0.42 & -0.21 & -0.30 & -0.30 & -0.27 & -0.22 & -0.15 & -0.06 & -0.02 & 0.05 & 0.11 & 0.26 & 0.26 & 0.34 & pro-cyclical lagged \\
\hline HP 3200 & 0.28 & -0.18 & -0.22 & -0.19 & -0.15 & -0.09 & -0.02 & 0.07 & 0.13 & 0.20 & 0.25 & 0.37 & 0.37 & 0.44 & pro-cyclical lagged \\
\hline BP $(1,5,8$ years $)$ & 0.32 & -0.39 & -0.50 & -0.55 & -0.53 & -0.47 & -0.37 & -0.26 & -0.15 & -0.04 & 0.06 & 0.18 & 0.31 & 0.43 & counter-cyclical lagged \\
\hline $\mathrm{BP}(1,5,12$ years $)$ & 0.17 & -0.48 & -0.51 & -0.50 & -0.44 & -0.36 & -0.25 & -0.14 & -0.02 & 0.09 & 0.20 & 0.31 & 0.43 & 0.53 & pro-cyclical lagged \\
\hline Average & 0.56 & -0.20 & -0.26 & -0.25 & -0.22 & -0.17 & -0.11 & -0.01 & 0.02 & 0.10 & 0.15 & 0.27 & 0.28 & 0.36 & pro-cyclical lagged \\
\hline THN & $\begin{array}{c}\text { relative } \\
\text { std }\end{array}$ & -6 & -5 & -4 & -3 & -2 & -1 & 0 & 1 & 2 & 3 & 4 & 5 & 6 & \\
\hline First diff filter & 0.92 & 0.03 & -0.02 & -0.12 & -0.21 & -0.12 & -0.18 & -0.11 & -0.08 & -0.06 & 0.09 & 0.13 & 0.23 & 0.28 & weak, pro-cyclical lagged \\
\hline Linear trend & 1.77 & -0.41 & -0.34 & -0.28 & -0.20 & -0.11 & -0.01 & 0.09 & 0.19 & 0.29 & 0.39 & 0.48 & 0.56 & 0.62 & pro-cyclical lagged \\
\hline HP 1600 & 1.12 & -0.25 & -0.28 & -0.32 & -0.36 & -0.36 & -0.34 & -0.29 & -0.17 & -0.02 & 0.14 & 0.28 & 0.41 & 0.51 & pro-cyclical lagged \\
\hline HP 3200 & 0.94 & -0.42 & -0.41 & -0.41 & -0.40 & -0.36 & -0.30 & -0.22 & -0.08 & 0.07 & 0.22 & 0.36 & 0.48 & 0.58 & pro-cyclical lagged \\
\hline $\mathrm{BP}(1,5,8$ years $)$ & 1.17 & -0.09 & -0.19 & -0.31 & -0.41 & -0.49 & -0.51 & -0.48 & -0.38 & -0.24 & -0.09 & 0.08 & 0.23 & 0.36 & counter-cyclical lagged \\
\hline $\mathrm{BP}(1,5,12$ years $)$ & 0.99 & -0.47 & -0.47 & -0.47 & -0.46 & -0.43 & -0.38 & -0.29 & -0.17 & -0.03 & 0.12 & 0.27 & 0.40 & 0.52 & pro-cyclical lagged \\
\hline Average & 1.15 & -0.27 & -0.29 & -0.32 & -0.34 & -0.31 & -0.29 & -0.22 & -0.12 & 0.00 & 0.15 & 0.27 & 0.39 & 0.48 & pro-cyclical lagged \\
\hline UNB & $\begin{array}{c}\text { relative } \\
\text { std }\end{array}$ & -6 & -5 & -4 & -3 & -2 & -1 & 0 & 1 & 2 & 3 & 4 & 5 & 6 & \\
\hline First diff filter & 41.64 & -0.08 & -0.04 & -0.11 & -0.24 & -0.19 & -0.18 & -0.24 & -0.16 & -0.11 & -0.04 & 0.04 & 0.06 & 0.10 & counter-cyclical lead \\
\hline Linear trend & 68.13 & -0.53 & -0.51 & -0.47 & -0.43 & -0.36 & -0.28 & -0.19 & -0.11 & -0.01 & 0.09 & 0.20 & 0.30 & 0.41 & counter-cyclical lead \\
\hline HP 1600 & 60.46 & -0.31 & -0.36 & -0.42 & -0.49 & -0.52 & -0.53 & -0.51 & -0.44 & -0.35 & -0.24 & -0.11 & 0.02 & 0.15 & counter-cyclical lead \\
\hline HP 3200 & 59.51 & -0.50 & -0.52 & -0.55 & -0.58 & -0.57 & -0.54 & -0.49 & -0.41 & -0.31 & -0.19 & -0.06 & 0.07 & 0.20 & counter-cyclical lead \\
\hline BP $(1,5,8$ years $)$ & 58.81 & 0.08 & -0.02 & -0.14 & -0.27 & -0.39 & -0.46 & -0.48 & -0.44 & -0.37 & -0.27 & -0.16 & -0.05 & 0.06 & counter-cyclical lead \\
\hline $\mathrm{BP}(1,5,12$ years $)$ & 58.13 & -0.49 & -0.56 & -0.62 & -0.68 & -0.71 & -0.71 & -0.68 & -0.61 & -0.52 & -0.40 & -0.26 & -0.12 & 0.03 & counter-cyclical contemp \\
\hline Average & 57.78 & -0.31 & -0.34 & -0.39 & -0.45 & -0.46 & -0.45 & -0.43 & -0.36 & -0.28 & -0.18 & -0.06 & 0.05 & 0.16 & counter-cyclical lead \\
\hline
\end{tabular}

Note: nominal fiscal variables are deflated using AWM's GDP deflator. 
Figure 1. The quarterly fiscal database: total government revenue (TOR) and expenditure (TOE)

Panel A. TOR. Smoothed and filtered estimates, not seasonally-adjusted (NSA, thick solid line), seasonally-adjusted (SA, light solid line) and 95\% confidence bands (dotted lines)
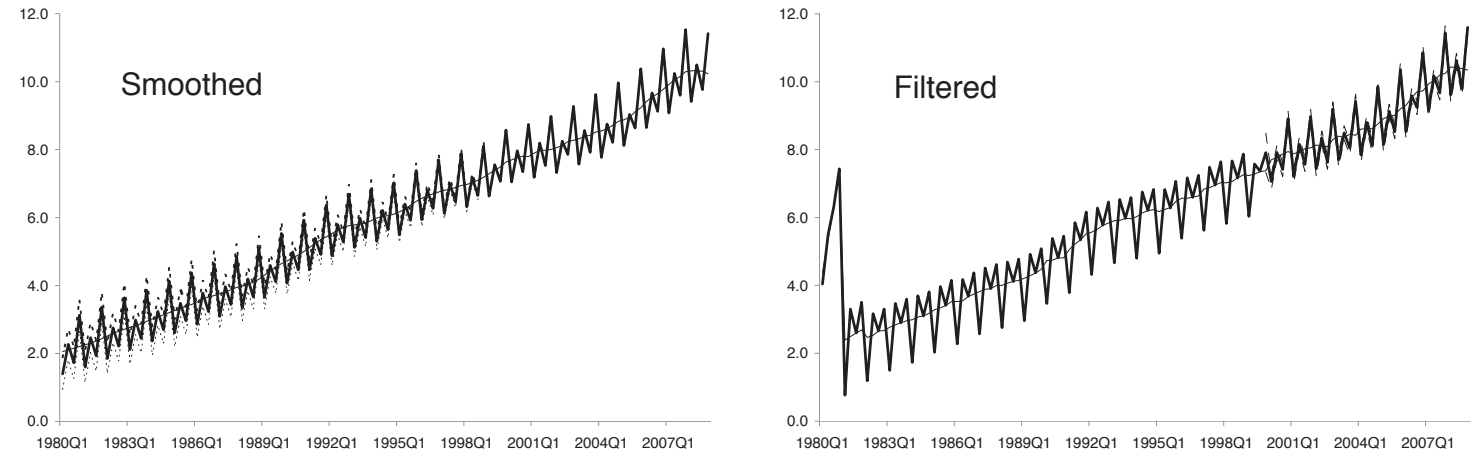

SA levels, smoothed \& filtered estimates

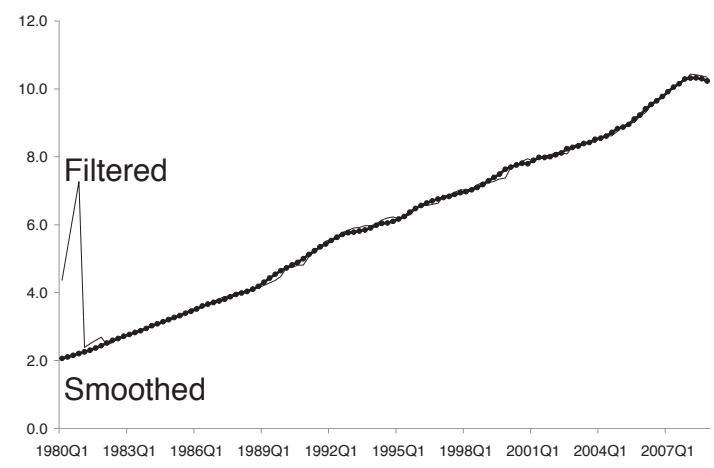

SA q-o-q growth rates, smoothed \& filtered

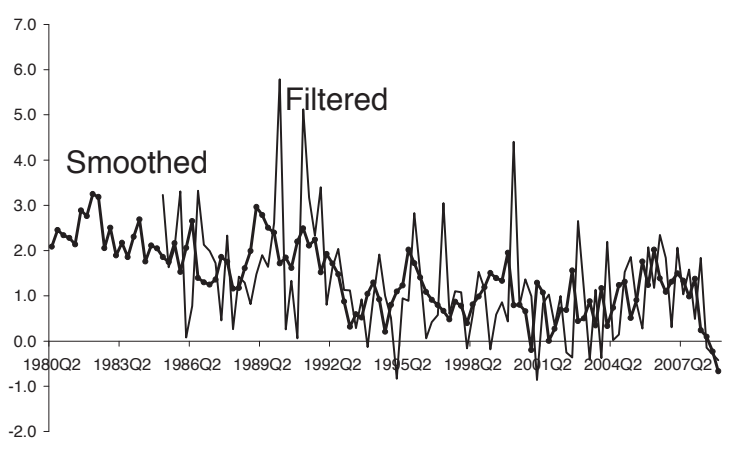

Panel B. TOE. Smoothed and filtered estimates, not seasonally-adjusted (NSA, thick solid line), seasonally-adjusted (SA, light solid line) and 95\% confidence bands (dotted lines)
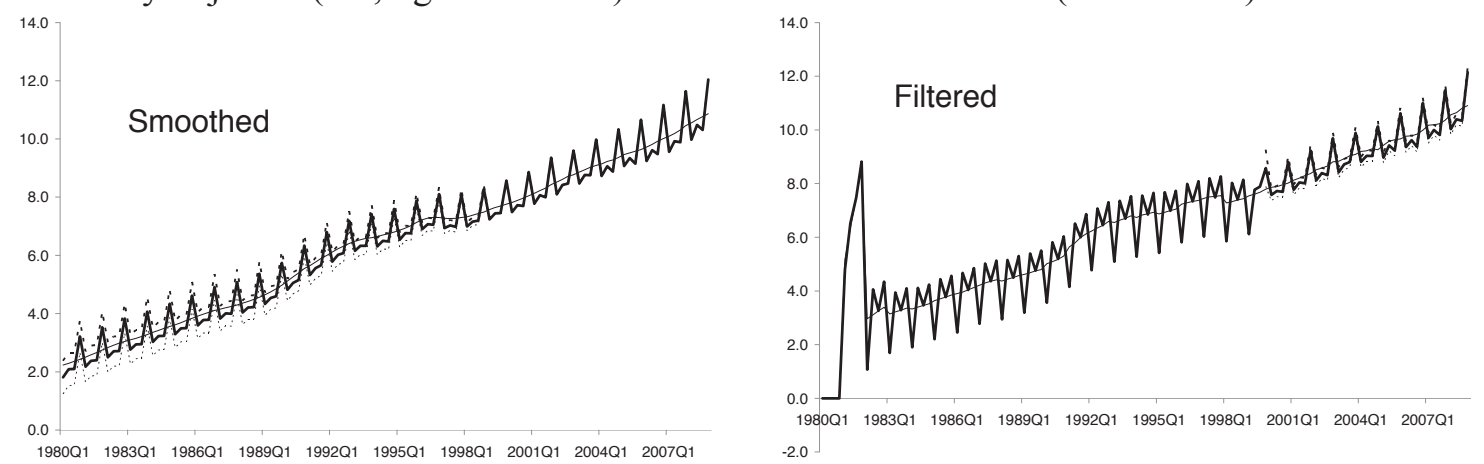

SA levels, smoothed \& filtered estimates

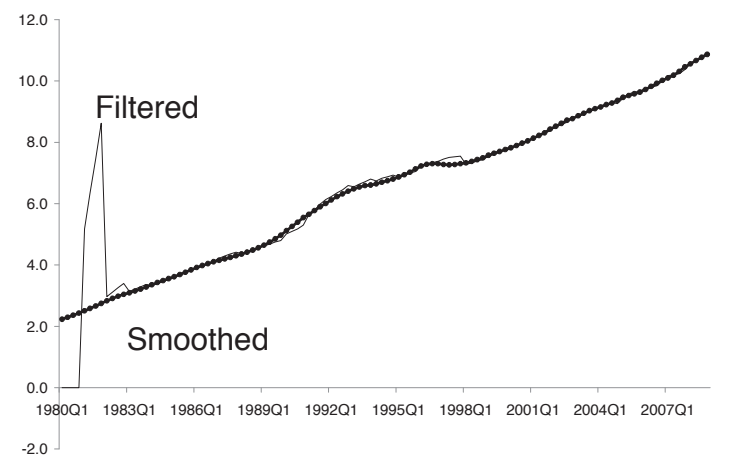

SA q-o-q growth rates, smoothed \& filtered

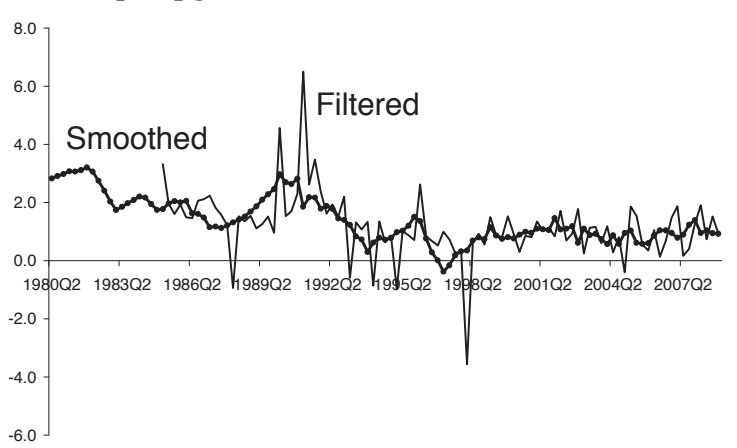


Figure 2. The quarterly fiscal database: total revenue and total revenue components (smoothed estimates). Quarter-on-quarter growth rates of seasonally-adjusted figures in nominal terms.

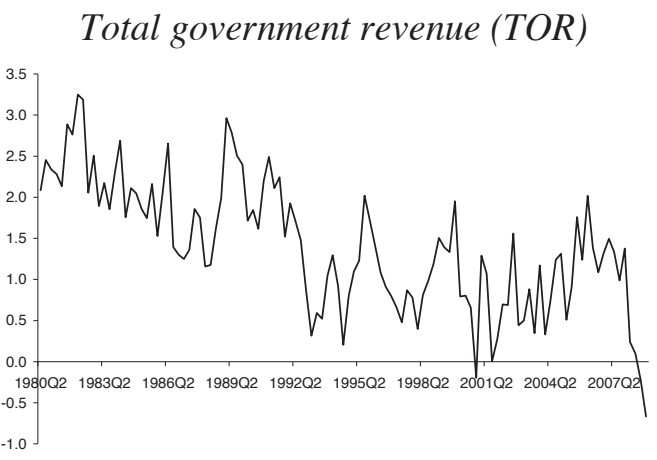

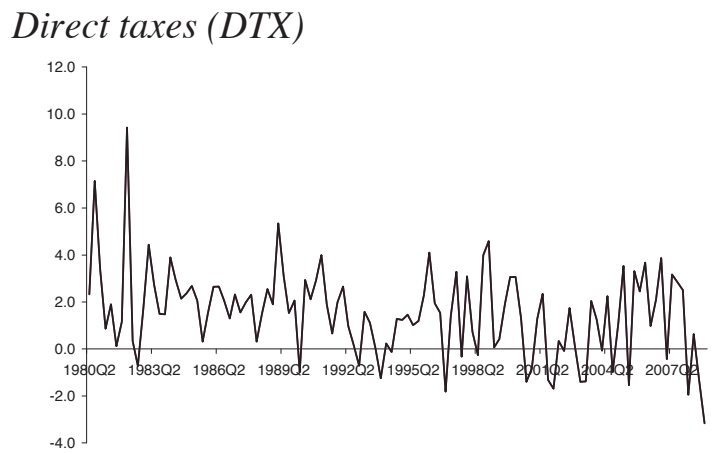

Social Security Contributions (SCT)

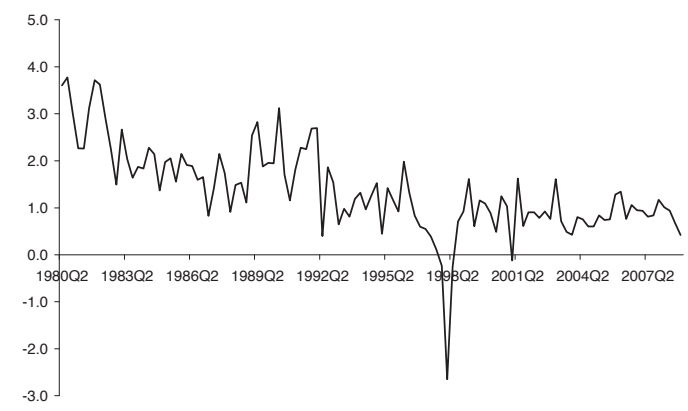

Indirect taxes (TIN)

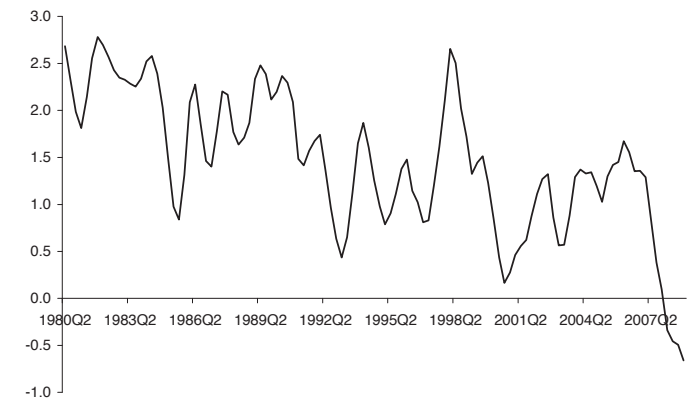

Direct taxes paid by households (DTH) and firms (DTE)

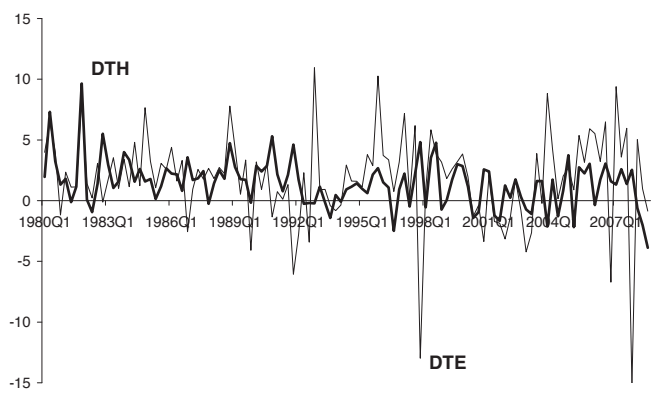

Social security contributions paid by employers (SCR) and other social contributions (SCE)

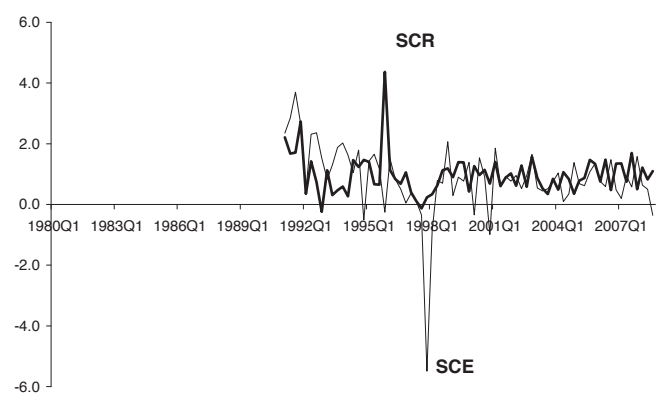

Other government revenue (OTOR)

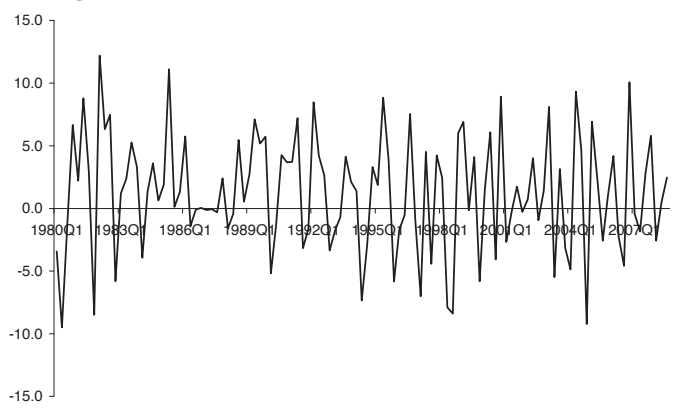


Figure 3. The quarterly fiscal database: total expenditure and total expenditure components (smoothed estimates). Quarter-on-quarter growth rates of seasonally-adjusted figures in nominal terms.

Total government expenditure (TOE)

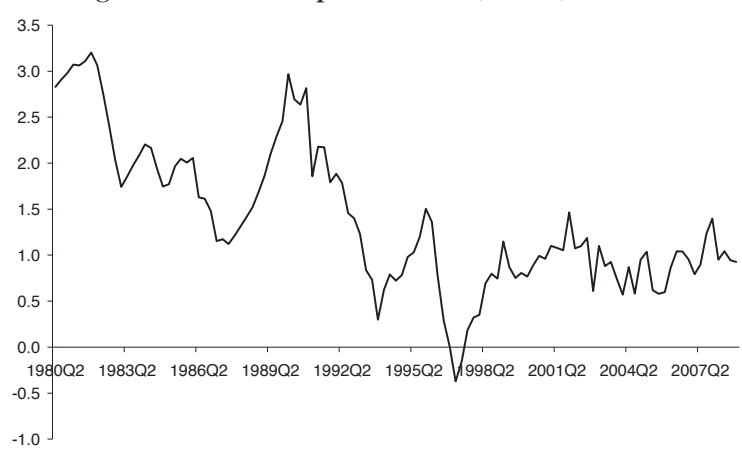

Government consumption (GCN)

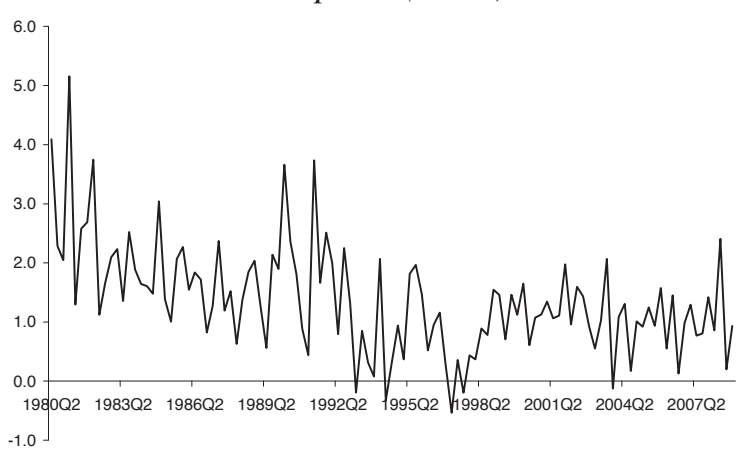

Unemployment benefits (UNB)

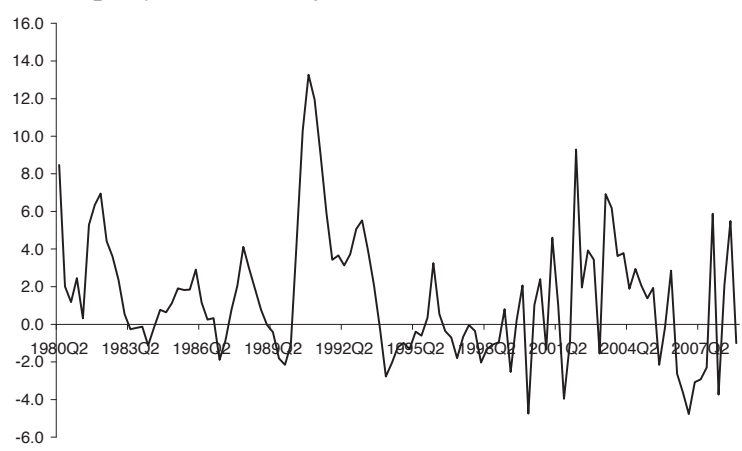

\section{Subsidies (SIN)}

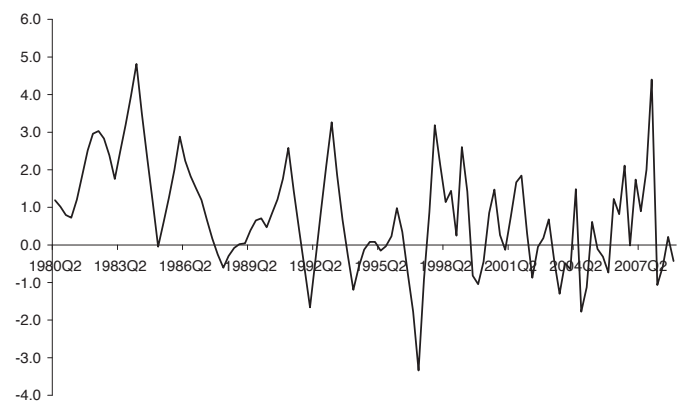

Transfers to households (THN)

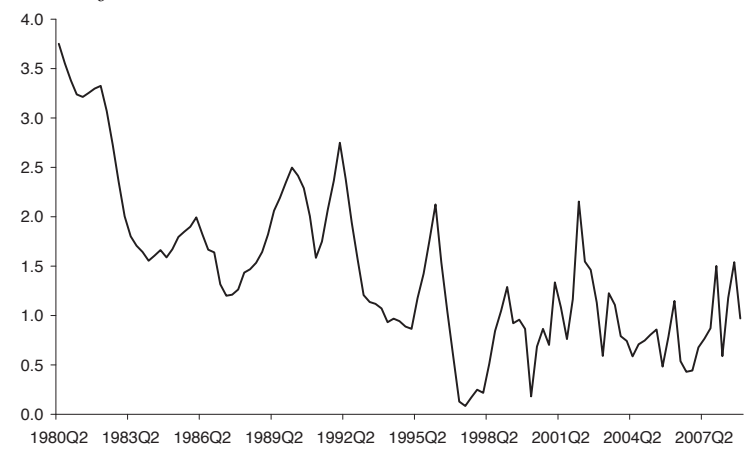

Government investment (GIN)

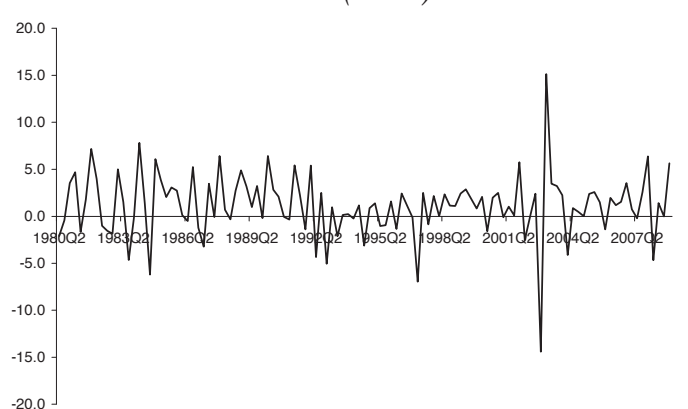

Interest payments (INP)

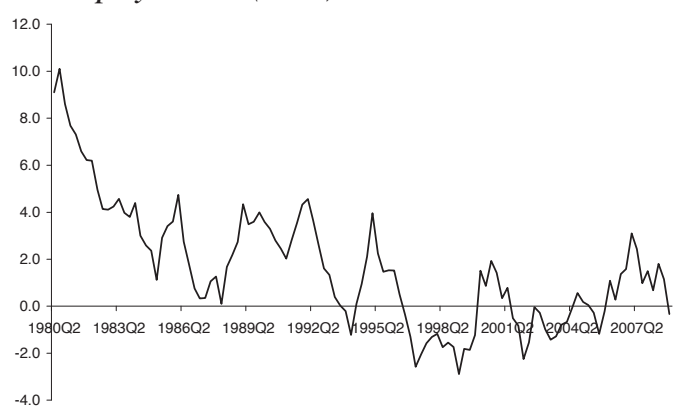

Other total expenditure (OTOE)

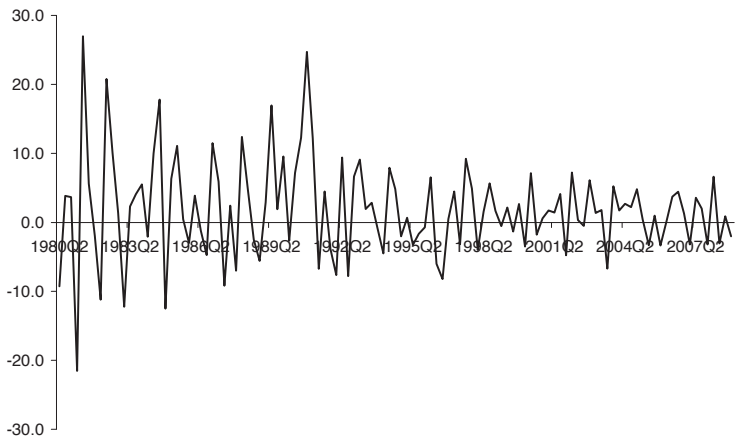


Figure 4. The quarterly fiscal database: decomposition of government consumption (smoothed estimates). Quarter-on-quarter growth rates of model-consistent seasonally-adjusted figures in nominal terms.
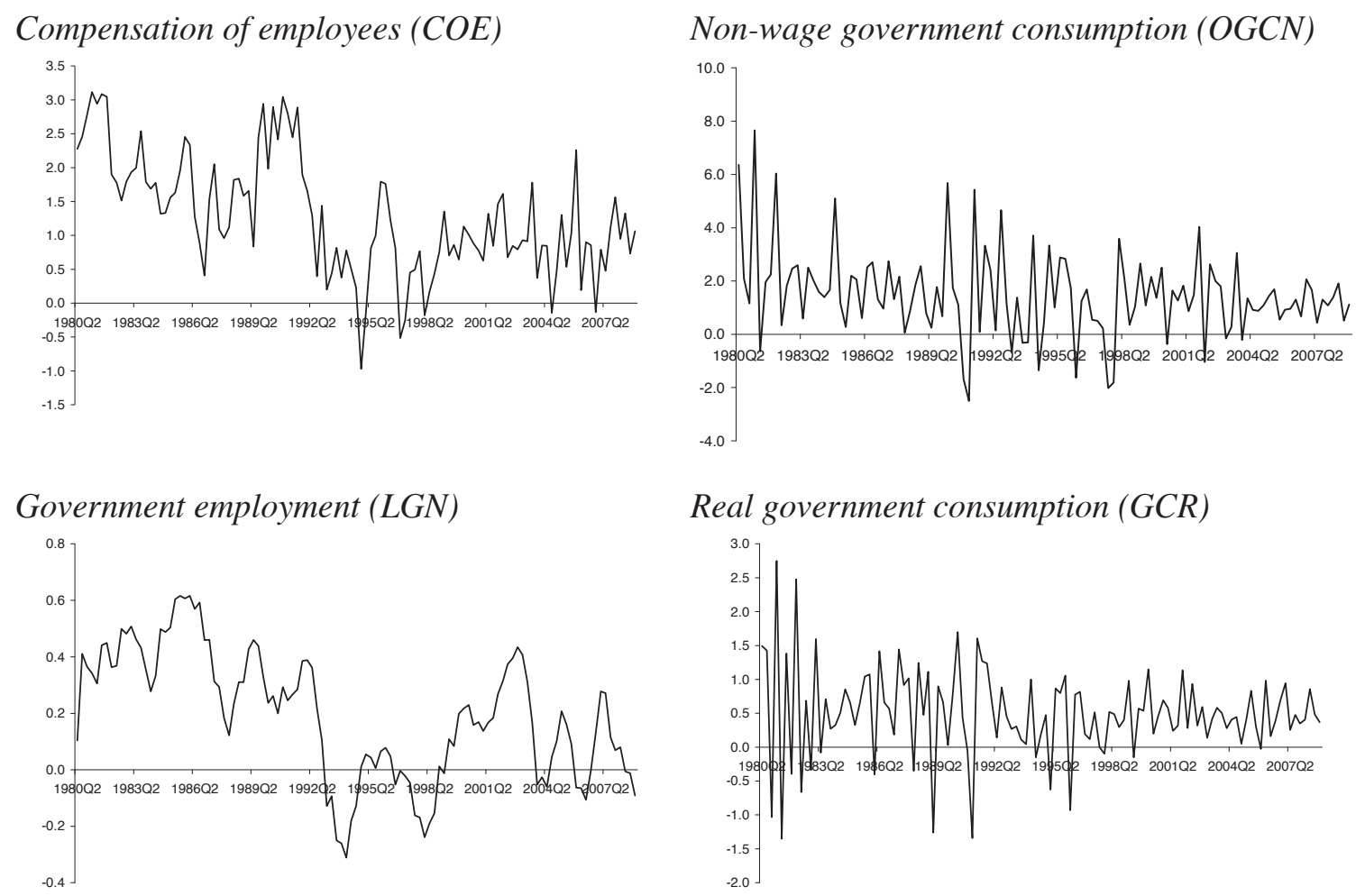
Figure 5. A comparative visual inspection regarding quarter-on-quarter growth rates of seasonally-adjusted series: quarterly database, AWM and database by Forni et al. (2009).

TOR: percentage differences in levels (not seasonally adjusted)

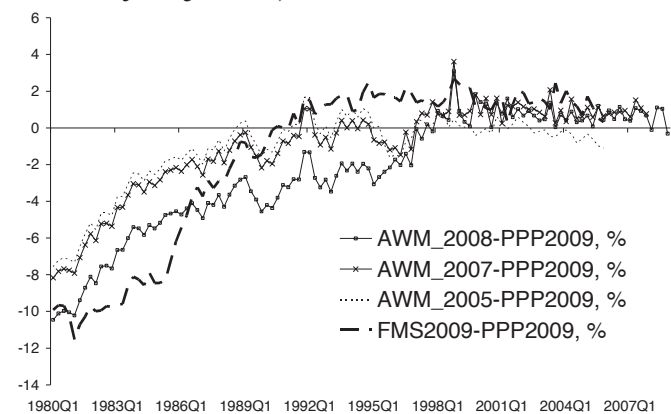

$T O E$ : percentage differences in levels (not seasonally adjusted)

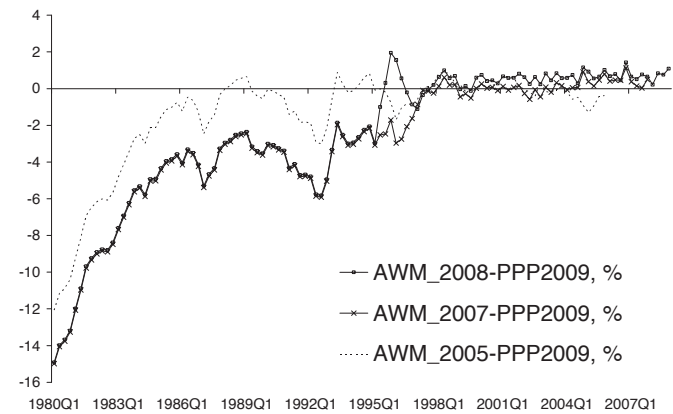

GCR: percentage differences in levels (not seasonally adjusted)

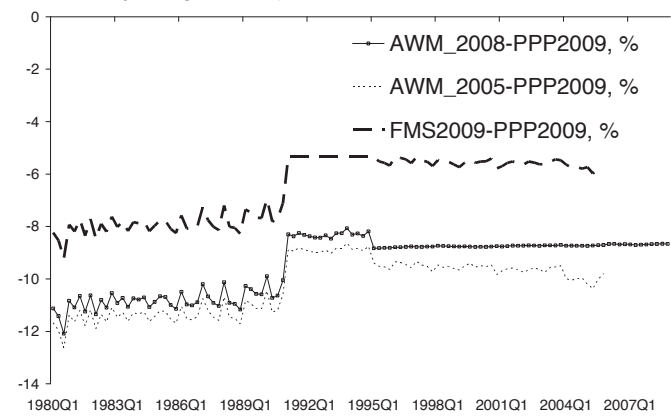

$T H N$ : percentage differences in levels (not seasonally adjusted)

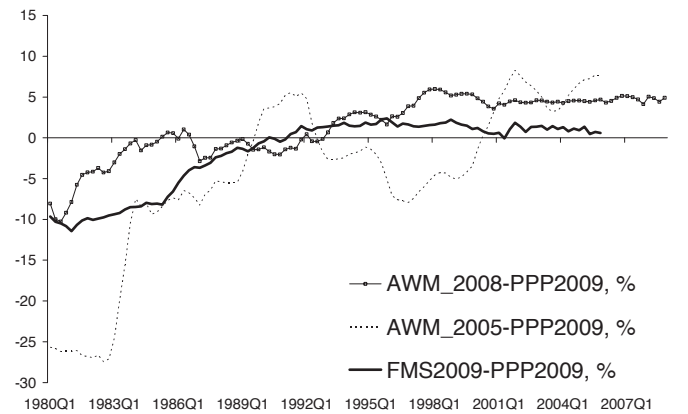

TOR: absolute differences in q-on-q growth rates of seasonally-adjusted series

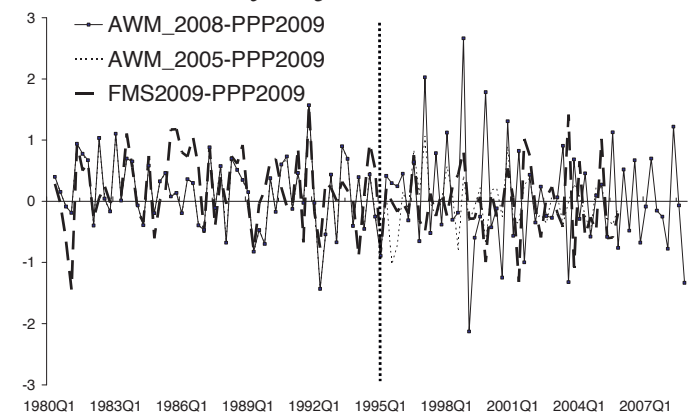

TOE: absolute differences in q-on-q growth rates of seasonally-adjusted series

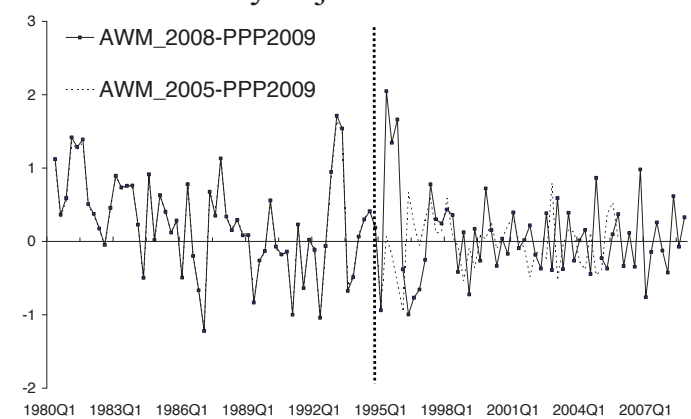

$G C R$ : absolute differences in q-on-q growth rates of seasonally-adjusted series

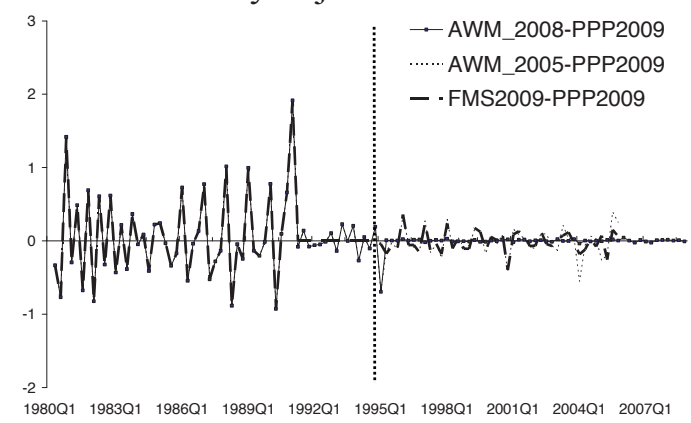

$T H N$ : absolute differences in q-on-q growth rates of seasonally-adjusted series

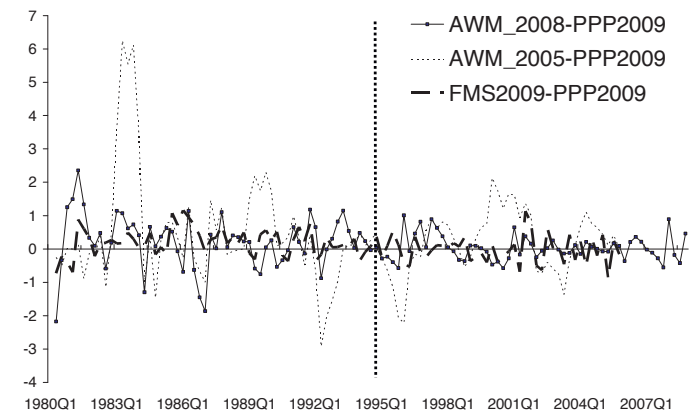


Figure 6. Some stylised facts of the real-time database: total government revenue (TOR)

Panel A. TOR: Evolution across vintages of quarter-on-quarter growth rates of seasonally-adjusted data for selected dates: 1980Q4, 1988Q4, 1996Q4, 2000Q4, 2004Q4, 2007 Q.

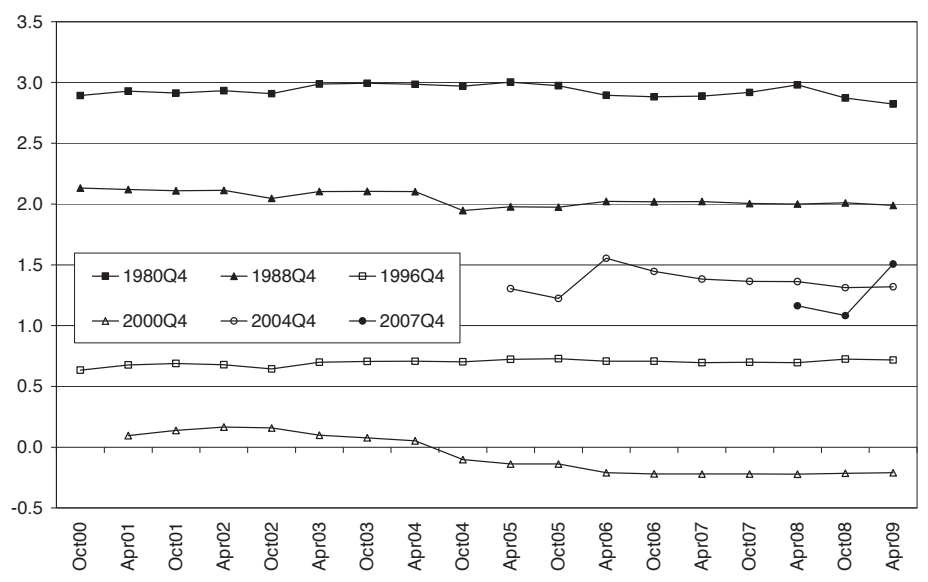

Panel B. TOR: average quarter-on-quart. growth rates of seasonally-adjusted data over four years Vintage

\begin{tabular}{|c|c|c|c|c|c|c|c|c|c|c|c|c|c|c|c|c|c|c|}
\hline Period & Oct00 & Apr01 & Oct01 & Apr02 & Oct02 & Apr03 & Oct03 & Apr04 & Oct04 & Apr05 & Oct05 & Apr06 & Oct06 & Apr07 & Oct07 & Apr08 & Oct08 & Apr09 \\
\hline 1980Q1-1983Q4 & 2.59 & 2.61 & 2.61 & 2.61 & 2.59 & 2.63 & 2.63 & 2.63 & 2.64 & 2.64 & 2.63 & 2.60 & 2.59 & 2.59 & 2.61 & 2.62 & 2.59 & 2.57 \\
\hline 1984Q1-1987Q4 & 1.83 & 1.83 & 1.83 & 1.83 & 1.84 & 1.83 & 1.83 & 1.83 & 1.84 & 1.84 & 1.84 & 1.83 & 1.83 & 1.83 & 1.83 & 1.83 & 1.83 & 1.83 \\
\hline 1988Q1-1991Q4 & 2.03 & 2.03 & 2.03 & 2.03 & 2.02 & 2.03 & 2.03 & 2.03 & 2.01 & 2.01 & 2.01 & 2.02 & 2.02 & 2.02 & 2.01 & 2.02 & 2.02 & 2.01 \\
\hline 1992Q1-1995Q4 & 1.12 & 1.12 & 1.12 & 1.12 & 1.13 & 1.12 & 1.12 & 1.12 & 1.11 & 1.12 & 1.11 & 1.12 & 1.12 & 1.12 & 1.12 & 1.12 & 1.12 & 1.12 \\
\hline 1996Q1-1999Q4 & - & - & - & & & - & & - & 1.06 & 1.06 & 1.06 & 1.07 & 1.05 & 1.05 & 1.05 & 1.05 & 1.05 & 1.05 \\
\hline 2001Q1-2004Q4 & - & - & - & - & - & - & - & & & 0.81 & 0.76 & 0.78 & 0.79 & 0.78 & 0.79 & 0.79 & 0.79 & 0.79 \\
\hline 2005Q1-2008Q1 & - & - & - & - & - & - & - & - & - & - & - & - & - & - & - & - & 1.20 & 1.19 \\
\hline & \multicolumn{18}{|c|}{ Correlation of vintages with interpolated q-fiscal database (1980Q1 - latest avaiable quarter) } \\
\hline & Oct00 & Apr01 & Oct01 & Apr02 & Oct02 & Apr03 & Oct03 & Apr04 & Oct04 & Apr05 & Oct05 & Apr06 & Oct06 & Apr07 & Oct07 & Apr08 & Oct08 & Apr09 \\
\hline & 0.95 & 0.96 & 0.96 & 0.95 & 0.95 & 0.95 & 0.95 & 0.95 & 0.96 & 0.96 & 0.96 & 0.96 & 0.97 & 0.97 & 0.97 & 0.96 & 0.98 & 0.98 \\
\hline
\end{tabular}

Panel C. TOR: average year-on-year growth rates of not seasonally-adjusted data over four years

Vintage

$\begin{array}{lccccccccccccccccccccc}\text { Period } & \text { Oct00 } & \text { Apr01 } & \text { Oct01 } & \text { Apr02 } & \text { Oct02 } & \text { Apr03 } & \text { Oct03 } & \text { Apr04 } & \text { Oct04 } & \text { Apr05 } & \text { Oct05 } & \text { Apr06 } & \text { Oct06 } & \text { Apr07 } & \text { Oct07 } & \text { Apr08 } & \text { Oct08 } & \text { Apr09 } \\ \text { 1982Q2-1986Q1 } & 9.23 & 9.22 & 9.21 & 9.22 & 9.21 & 9.21 & 9.21 & 9.21 & 9.66 & 9.67 & 9.64 & 9.64 & 9.64 & 9.62 & 9.62 & 9.61 & 9.62 & 9.63 \\ \text { 1986Q2-1990Q1 } & 7.50 & 7.49 & 7.50 & 7.49 & 7.51 & 7.50 & 7.50 & 7.50 & 7.67 & 7.67 & 7.67 & 7.68 & 7.71 & 7.70 & 7.70 & 7.69 & 7.71 & 7.72 \\ \text { 1988Q1-1994Q1 } & 6.61 & 6.61 & 6.61 & 6.62 & 6.62 & 6.61 & 6.61 & 6.61 & 6.75 & 6.72 & 6.71 & 6.71 & 6.70 & 6.70 & 6.70 & 6.71 & 6.68 & 6.68 \\ \text { 1994Q2-1998Q1 } & 4.15 & 4.14 & 4.10 & 4.11 & 4.15 & 4.13 & 4.12 & 4.12 & 4.13 & 4.16 & 4.15 & 4.12 & 4.10 & 4.09 & 4.09 & 4.09 & 4.10 & 4.10 \\ \text { 1998Q2-2002Q1 } & - & - & - & 3.74 & 3.70 & 3.77 & 3.78 & 3.81 & 3.80 & 3.79 & 3.82 & 3.85 & 3.80 & 3.80 & 3.81 & 3.80 & 3.80 & 3.80 \\ \text { 2002Q2-2004Q1 } & - & - & - & - & - & - & - & - & 2.90 & 2.87 & 2.97 & 2.91 & 2.88 & 2.86 & 2.87 & 2.88 & 2.87 & 2.87 & 2.87 \\ \text { 2004Q4-2008Q3 } & - & - & - & - & - & - & - & - & - & - & - & - & - & - & - & - & 4.62 & 4.66\end{array}$

Correlation of vintages with interpolated q-fiscal database (1980Q1 - latest avaiable quarter) 
Figure 7. Some stylised facts of the real-time database: total government expenditure (TOE)

Panel A. TOE: Evolution across vintages of quarter-on-quarter growth rates of seasonally-adjusted data for selected dates: 1980Q4, 1988Q4, 1996Q4, 2000Q4, 2004Q4, 2007 Q.

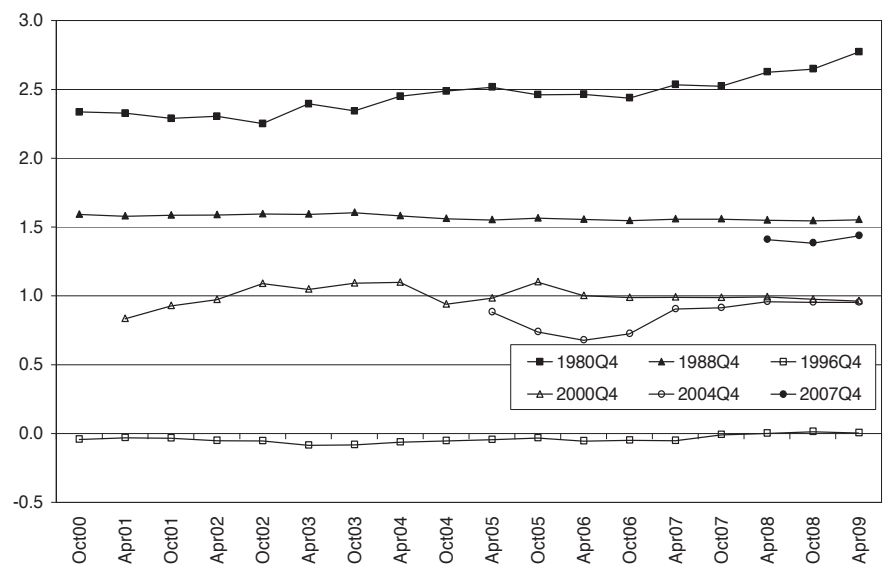

Panel B. TOE: average quarter-on-quart. growth rates of seasonally-adjusted data over four years Vintage

\begin{tabular}{|c|c|c|c|c|c|c|c|c|c|c|c|c|c|c|c|c|c|c|}
\hline Period & Oct00 & Apr01 & Oct01 & Apr02 & Oct02 & Apr03 & Oct03 & Apr04 & Oct04 & Apr05 & Oct05 & Apr06 & Oct06 & Apr07 & Oct07 & Apr08 & Oct08 & Apr09 \\
\hline 1-1983Q4 & & & & 2.37 & & & & & 2.43 & 2.43 & 2.42 & & 2.41 & 2.44 & 2.43 & & 2.47 & \\
\hline & & & & & & & & & & & & & & & & & 72 & \\
\hline & & & & & & & & & & & & & & & & & & \\
\hline $95 \mathrm{Q} 4$ & & & 1.12 & & & & & & & & & & & & & & .11 & 1.1 \\
\hline $999 \mathrm{Q} 4$ & - & - & - & & & & & 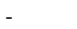 & 0.53 & & & & & & & & 0.52 & 0. \\
\hline $04 \mathrm{Q} 4$ & - & - & - & - & - & - & - & & & 0.97 & 0.9 & 0.9 & 0.9 & 0.9 & 0.9 & 0.95 & 0.96 & \\
\hline 005Q1-2008Q1 & - & - & - & - & - & - & - & - & - & - & - & - & - & - & - & - & 0.90 & 0.9 \\
\hline
\end{tabular}

Correlation of vintages with interpolated q-fiscal database (1980Q1 - latest avaiable quarter)

Oct00 Apr01 Oct01 Apr02 Oct02 Apr03 Oct03 Apr04 Oct04 Apr05 Oct05 Apr06 Oct06 Apr07 Oct07 Apr08 Oct08 Apr09 \begin{tabular}{llllllllllllllllll}
\hline 0.94 & 0.95 & 0.95 & 0.94 & 0.93 & 0.94 & 0.93 & 0.94 & 0.95 & 0.95 & 0.95 & 0.95 & 0.96 & 0.95 & 0.95 & 0.96 & 0.96 & 0.96
\end{tabular}

Panel C. TOE: average year-on-year growth rates of not seasonally-adjusted data over four years

Vintage

\begin{tabular}{|c|c|c|c|c|c|c|c|c|c|c|c|c|c|c|c|c|c|c|}
\hline Period & Oct00 & Apr01 & Oct01 & Apr02 & Oct02 & Apr03 & Oct03 & Apr04 & Oct04 & Apr05 & Oct05 & Apr06 & Oct06 & Apr07 & Oct07 & Apr08 & Oct08 & Apr09 \\
\hline 983Q4 & 10.15 & 10.15 & 10.11 & 10.13 & 10.07 & 10.21 & 10.15 & 10.27 & 10.48 & 10.50 & 10.45 & 10.46 & 10.44 & 10.53 & 10.52 & 10.62 & 10.65 & 10.79 \\
\hline & & & & & & & & & & & & & & & & & 53 & 7. \\
\hline & & & & & & & & & & & & & & & & & & 8. \\
\hline & 4 & 4.60 & 4.60 & 4.60 & 4.60 & 4.60 & 4.60 & 4.60 & 4. & & & & 4.6 & & & & 4.63 & 4.6 \\
\hline $99 \mathrm{Q} 4$ & - & - & - & - & - & - & - & - & 2.46 & & 2. & & 2.4 & & & 42 & 2.42 & 2.4 \\
\hline 01Q1-2004Q4 & - & - & - & - & - & - & - & - & 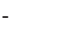 & 3.91 & 3.74 & 3.78 & 3.81 & 3.81 & 3.83 & 3.87 & 3.88 & 3.8 \\
\hline $05 \mathrm{Q} 1-2008 \mathrm{Q} 1$ & & 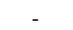 & & - & ـ & ـ & ـ & - & - & - & - & - & _- & _- & _- & - & 3.48 & 3.53 \\
\hline
\end{tabular}

Correlation of vintages with interpolated q-fiscal database (1980Q1 - latest avaiable quarter)

Oct00 Apr01 Oct01 Apr02 Oct02 Apr03 Oct03 Apr04 Oct04 Apr05 Oct05 Apr06 Oct06 Apr07 Oct07 Apr08 Oct08 Apr09

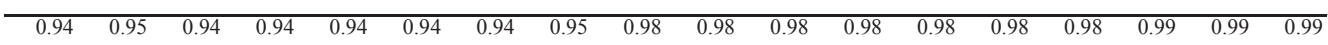




\section{European Central Bank Working Paper Series}

For a complete list of Working Papers published by the ECB, please visit the ECB's website (http://www.ecb.europa.eu).

1086 "Euro area money demand: empirical evidence on the role of equity and labour markets" by G. J. de Bondt, September 2009.

1087 "Modelling global trade flows: results from a GVAR model” by M. Bussière, A. Chudik and G. Sestieri, September 2009.

1088 "Inflation perceptions and expectations in the euro area: the role of news" by C. Badarinza and M. Buchmann, September 2009.

1089 "The effects of monetary policy on unemployment dynamics under model uncertainty: evidence from the US and the euro area" by C. Altavilla and M. Ciccarelli, September 2009.

1090 “New Keynesian versus old Keynesian government spending multipliers” by J. F. Cogan, T. Cwik, J. B. Taylor and V. Wieland, September 2009.

I09I “Money talks” by M. Hoerova, C. Monnet and T. Temzelides, September 2009.

1092 "Inflation and output volatility under asymmetric incomplete information" by G. Carboni and M. Ellison, September 2009.

1093 "Determinants of government bond spreads in new EU countries" by I. Alexopoulou, I. Bunda and A. Ferrando, September 2009.

1094 “Signals from housing and lending booms" by I. Bunda and M. Ca'Zorzi, September 2009.

1095 “Memories of high inflation” by M. Ehrmann and P. Tzamourani, September 2009.

1096 “The determinants of bank capital structure” by R. Gropp and F. Heider, September 2009.

1097 “Monetary and fiscal policy aspects of indirect tax changes in a monetary union” by A. Lipińska and L. von Thadden, October 2009.

1098 "Gauging the effectiveness of quantitative forward guidance: evidence from three inflation targeters" by M. Andersson and B. Hofmann, October 2009.

1099 "Public and private sector wages interactions in a general equilibrium model” by G. Fernàndez de Córdoba, J.J. Pérez and J. L. Torres, October 2009.

I 100 "Weak and strong cross section dependence and estimation of large panels" by A. Chudik, M. Hashem Pesaran and E. Tosetti, October 2009.

I IOI "Fiscal variables and bond spreads - evidence from eastern European countries and Turkey" by C. Nickel, P. C. Rother and J. C. Rülke, October 2009.

II 02 "Wage-setting behaviour in France: additional evidence from an ad-hoc survey" by J. Montornés and J.-B. Sauner-Leroy, October 2009.

I I 03 “Inter-industry wage differentials: how much does rent sharing matter?” by P. Du Caju, F. Rycx and I. Tojerow, October 2009. 
I 104 "Pass-through of external shocks along the pricing chain: a panel estimation approach for the euro area" by B. Landau and F. Skudelny, November 2009.

I 105 "Downward nominal and real wage rigidity: survey evidence from European firms" by J. Babecký, P. Du Caju, T. Kosma, M. Lawless, J. Messina and T. Rõõm, November 2009.

I 106 "The margins of labour cost adjustment: survey evidence from European firms" by J. Babecký, P. Du Caju, T. Kosma, M. Lawless, J. Messina and T. Rõõm, November 2009.

I 107 “Interbank lending, credit risk premia and collateral” by F. Heider and M. Hoerova, November 2009.

I 108 "The role of financial variables in predicting economic activity" by R. Espinoza, F. Fornari and M. J. Lombardi, November 2009.

I 109 “What triggers prolonged inflation regimes? A historical analysis.” by I. Vansteenkiste, November 2009.

I I 10 "Putting the New Keynesian DSGE model to the real-time forecasting test" by M. Kolasa, M. Rubaszek and P. Skrzypczyński, November 2009.

I I I "A stable model for euro area money demand: revisiting the role of wealth" by A. Beyer, November 2009.

I I 12 "Risk spillover among hedge funds: the role of redemptions and fund failures" by B. Klaus and B. Rzepkowski, November 2009.

I I I 3 "Volatility spillovers and contagion from mature to emerging stock markets" by J. Beirne, G. M. Caporale, M. Schulze-Ghattas and N. Spagnolo, November 2009.

I I I4 "Explaining government revenue windfalls and shortfalls: an analysis for selected EU countries” by R. Morris, C. Rodrigues Braz, F. de Castro, S. Jonk, J. Kremer, S. Linehan, M. Rosaria Marino, C. Schalck and O. Tkacevs.

I I I5 "Estimation and forecasting in large datasets with conditionally heteroskedastic dynamic common factors" by L. Alessi, M. Barigozzi and M. Capasso, November 2009.

I I 16 "Sectorial border effects in the European single market: an explanation through industrial concentration" by G. Cafiso, November 2009.

II 17 "What drives personal consumption? The role of housing and financial wealth" by J. Slacalek, November 2009.

I I 8 "Discretionary fiscal policies over the cycle: new evidence based on the ESCB disaggregated approach" by L. Agnello and J. Cimadomo, November 2009.

I I 9 "Nonparametric hybrid Phillips curves based on subjective expectations: estimates for the euro area" by M. Buchmann, December 2009.

I I 20 "Exchange rate pass-through in central and eastern European member states" by J. Beirne and M. Bijsterbosch, December 2009.

II 2 I "Does finance bolster superstar companies? Banks, Venture Capital and firm size in local U.S. markets" by A. Popov, December 2009.

I I 22 "Monetary policy shocks and portfolio choice” by M. Fratzscher, C. Saborowski and R. Straub, December 2009.

II 23 “Monetary policy and the financing of firms" by F. De Fiore, P. Teles and O. Tristani, December 2009.

I I 24 "Balance sheet interlinkages and macro-financial risk analysis in the euro area" by O. Castrén and I. K. Kavonius, December 2009. 
I I 25 “Leading indicators in a globalised world” by F. Fichtner, R. Rüffer and B. Schnatz, December 2009.

I 126 "Liquidity hoarding and interbank market spreads: the role of counterparty risk" by F. Heider, M. Hoerova and C. Holthausen, December 2009.

I 27 “The Janus-headed salvation: sovereign and bank credit risk premia during 2008-09” by J. W. Ejsing and W. Lemke, December 2009.

I 28 "EMU and the adjustment to asymmetric shocks: the case of Italy" by G. Amisano, N. Giammarioli and L. Stracca, December 2009.

II 29 "Determinants of inflation and price level differentials across the euro area countries" by M. Andersson, K. Masuch and M. Schiffbauer, December 2009.

I I 30 “Monetary policy and potential output uncertainty: a quantitative assessment” by S. Delle Chiaie, December 2009.

II3I "What explains the surge in euro area sovereign spreads during the financial crisis of 2007-09?" by M.-G. Attinasi, C. Checherita and C. Nickel, December 2009.

I I 32 "A quarterly fiscal database for the euro area based on intra-annual fiscal information" by J. Paredes, D. J. Pedregal and J. J. Pérez, December 2009. 
